\title{
Impacts of climate change on suitability zonation for potato cultivation in Jilin Province, Northeast China
}

\section{Yaqiu Zhu}

Institute of Agricultural Resources and Regional Planning $₫$ Chinese Academy of Agricultural Sciences

\section{Qiang Yu}

Institute of Agricultural Resources and Regional Planning $₫$ Chinese Academy of Agricultural Sciences

Qiyou Luo

Institute of Agricultural Resources and Regional Planning $₫$ Chinese Academy of Agricultural Sciences

Hua Zhang

Institute of Agricultural Resources and Regional Planning $₫$ Chinese Academy of Agricultural Sciences

\section{Jinling Zhao}

State Key Laboratory of Vegetation and Environmental Change, Institute of Botany, Chinese Academy of

Sciences

\section{Zhanghong Ju}

Institute of Agricultural Resources and Regional Planning $₫$ Chinese Academy of Agricultural Sciences

\section{Yating Du}

Institute of Agricultural Resources and Regional Planning $₫$ Chinese Academy of Agricultural Sciences

Yadong Yang ( $\nabla$ yangyadong@caas.cn )

Institute of Agricultural Resources and Regional Planning $₫$ Chinese Academy of Agricultural Sciences

\section{Research Article}

Keywords: AHP-PCA, GIS, Suitable, Jilin Province, regional

Posted Date: January 22nd, 2021

DOl: https://doi.org/10.21203/rs.3.rs-147444/v1

License: (c) (i) This work is licensed under a Creative Commons Attribution 4.0 International License. Read Full License 

for potato cultivation in Jilin Province, Northeast China

\author{
Yaqiu Zhu1, Qiang Yu1,*, Qiyou Luo', Hua Zhang', Jinling Zhao², Zhanghong \\ Ju', Yating Du${ }^{1}$ \&Yadong Yang ${ }^{1, *}$
}

${ }^{1}$ Institute of Agricultural Resources and Regional Planning, Chinese Academy of Agricultural Sciences, Beijing, 100081, China.

${ }^{2}$ State Key Laboratory of Vegetation and Environmental Change, Institute of Botany, Chinese Academy of Sciences, Beijing, 100093, China.

* email: yuqiang@caas.cn; yangyadong@caas.cn

\begin{abstract}
Global climate change is causing notable shifts in the environmental suitability of the main regions involved in potato cultivation and has, thus, changed the production potential of potatoes. These shifts can be mapped at fine scales to better understand climate change within areas of potato cultivation and to find infrastructural- and breeding-based solutions. As a case study, we have identified and mapped the structural and spatial shifts that occurred in areas suitable for potato cultivation in Jilin Province, China. We identified a discontinuity in climate change trends between 1961 and 2018 based on data for Jilin Province, and analyzed the averages and linear trends for six important climatic parameters. We used the averages of these climatic parameters to establish climate models for the province and determined cultivation using a multi-criterion, decision-based model that integrates AHP-PCA and GIS. We mapped the environmentally suitable areas for potato cultivation at a 3-km resolution based on the geo-climate model for each time period and analyzed differences between them. We found that "Most suitable" areas for potato cultivation are mainly distributed in the central area of Jilin Province, "Suitable" areas were located in the northwestern plains, and "Subsuitable" areas in the eastern mountainous areas. In contrast, "Not suitable" areas occur mainly in the high-altitude areas in the east. The areas of "Most suitable" and "Suitable" areas for potato cultivation in Jilin Province are increasing, with increasing rates of $0.37 \times 1,000 \mathrm{~km}^{2}$ decade $^{-1}\left(R^{2}=0.58, P<0.01\right)$ and $0.20 \times 1,000 \mathrm{~km}^{2}\left(R^{2}=0.28, P<0.01\right)$, respectively, while the extent of "Sub-suitable" areas is decreasing, with a decreasing rate of $0.58 \times 1,000 \mathrm{~km}^{2} \mathrm{decade}^{-1}$ $\left(R^{2}=0.53, P<0.05\right)$. The area of "Not suitable" areas has undergone little change. "Most suitable" and "Suitable" areas for potato cultivation showed a trend towards northward expansion. Overall, our results suggest that global climate change has had a positive impact on potato cultivation in Jilin Province over the past 58 years.
\end{abstract}

\title{
Introduction
}

According to the Intergovernmental Panel on Climate Change (IPCC 2013) reports ${ }^{1}$, the global surface temperature has increased by $0.85{ }^{\circ} \mathrm{C}$ in the past 130 years, especially in the high latitudes of the Northern Hemisphere. As with other areas of the world, the temperature of Jilin Province has been experiencing an increase for the last six decades ${ }^{2,3}$. Jilin is located in the Northeast China, and its latitude makes it relatively highly susceptible to the effects of climate change within the temperate latitudes ${ }^{4}$. Jilin Province is one of the main potato-producing regions in China ${ }^{5}$. The province is rich in arable land resources and has a climate and geographical environment highly conducive to the growth and 
development of potatoes. Within Jilin Province, long-term and high spatial resolution research on potato cultivation provides a globally and nationally critical reference that is significant for promoting economic growth and development within the potato industry.

In general, higher temperatures increase the rate of crop growth and development, which influence yield ${ }^{6-8}$, and climate change leads to shifts in the suitable geographic ranges for the growth of specific crops and cultivars ${ }^{9,10}$. Moreover, in some cases, the phenology of crop plants is changing within the areas where they are cultivated, leading to temporal shifts in production with major economic impacts ${ }^{11,12}$. Combined, these two factors can lead to major changes to crop productivity within municipalities and broader regions, such as already observed for soybean production and rice cultivation ${ }^{13,14}$. In turn, this affects local, regional, and global food availability and security ${ }^{15}$. Global climate change has shifted the climatic suitability for crops in a region, particularly in the northern high latitudes ${ }^{16-18}$, which should not be overlooked by farmers.

Globally, potato (Solanum tuberosum L.) is the fourth most widely cultivated crop after maize, rice, and wheat ${ }^{19}$, with more than 91.9 million tons produced annually across an area of about 4,789.5 thousand hectares, with average yield of $19.1 \mathrm{t} \mathrm{ha}^{-1}$ in China ${ }^{20}$. In 2015, China launched the potato staple food strategy, which acknowledges and facilitates the role of potatoes in maintaining food security ${ }^{21-22}$. However, potato cultivation faces possible challenges due to ongoing anthropogenic climate change ${ }^{23-28}$, which is impacting many agricultural systems ${ }^{29-31}$. Several studies predicted an overall decrease in potato yield under the effect of global climate change in Eastern Europe and northern America $^{32,33}$. However, higher temperatures in England and $\mathrm{Wales}^{34}$, southern Brazil ${ }^{35}$, and within the mid-latitudes and tropical highlands ${ }^{33,36}$ are predicted to benefit potato yield. Thus, the present understanding of the impacts of climate change on potato yield appears to vary to opposite extremes by regions.

Ecological suitability is defined as the degree of agreement to which actual temperature, light, water, soil, and other climatic conditions satisfy the requirements of crop growth without considering other limiting factors. A high degree of agreement means strong suitability and good crop growth and development ${ }^{37}$. Studies on suitability could offer scientific evidence to reflect yield, quality, and layout of crops to a certain extent, as well as to promote the crop distribution under the effect of climate change ${ }^{39-41}$. Therefore, to obtain information on geographic shifts of suitable areas for crop cultivation under climatic conditions is the starting point for adaptation planning in agriculture ${ }^{42}$.

Previous case studies on potato cultivation involve breeding cultivar improvement, agro-technique development ${ }^{43-}$ ${ }^{44}$, field experiment, and potato yield estimation ${ }^{45-47}$. Many researchers ${ }^{48-49}$ have particularly focused on the development of potato industry. However, to our knowledge, no systematic study on the estimation of the variation of ecologically suitable areas under the influence of climate change has been reported for potato cultivation in Jilin Province.

The aim of this study is to identify shifts occurring in the spatial distribution of ecologically suitable areas for potato cultivation within Jilin Province, China between 1961 and 2018 under the influence of climate change. Here, the interannual variations of climatic factors were analyzed, and temporal and spatial distributions of suitable areas were estimated for climate change impacts across Jilin Province using gridded and point-based historical climate datasets. The map for each criterion was prepared using ArcGIS with weight values obtained from a widely used evaluation model AHP-PCA. These maps were combined to generate suitability maps for potato cultivation by using comprehensive ecological suitability indexes. We report the agro-climato-edaphic zonation for potato cultivation in Jilin Province. During the analysis, the soil factors were constant, and only the influence of climatic factors on changes in suitable areas was considered. The objectives of this study were to: (i) characterize the trends for six climatic factors between 1961 and 2018; (ii) analyze the variation of spatial distribution of climate inclination rates across the study area from 1961 to 2018; (iii) identify shifts occurring in the temporal and spatial distributions of suitable areas for potato cultivation in Jilin Province between 1961 and 2018; (iv) analyze trends in the climate-driven suitability zonation across Jilin Province; and (v) explore changes in the area of suitability zonation for potato cultivation in Jilin Province between 1961 and 2018. 


\section{Materials and methods}

\section{Study area}

This study was conducted in Jilin Province, which is located in the center of Northeast China $\left(40^{\circ} 52^{\prime} \mathrm{N}-46^{\circ} 18^{\prime} \mathrm{N}\right.$, $121^{\circ} 38^{\prime} \mathrm{E}-131^{\circ} 19^{\prime} \mathrm{E}$ ) and covers an area of approximately $187,400 \mathrm{~km}^{2}$, with an elevation varying from $5 \mathrm{~m}$ to 2,691 $\mathrm{m}$ (Fig.1). The study area has a temperate continental monsoon climate and is climatologically humid, semi-humid, and semi-arid from the southeast to the northwest. The annual mean temperature and annual total precipitation form a southeast-northwest gradient; the eastern part is relatively humid and rainy while the western is dry in the summer months. Generally, $70-80 \%$ of the annual precipitation occurs from June to September, with the most abundant rainfall in the east. The long-term average annual temperature and average annual rainfall are $5.8{ }^{\circ} \mathrm{C}$ and $687.0 \mathrm{~mm}$, respectively ${ }^{50}$. Crop cultivation is mostly concentrated in the black soil region ${ }^{51}$. The soil types of cultivated lands mainly include black soil, sand, and paddy soil, which are suitable for potato growth.

Potato growth is highly dependent on temperature and light. Jilin Province, as one of the main potato-producing areas in China, possesses sufficient sunlight and exhibits large temperature difference between day and night. Generally, potato cultivation occurs from April to May, depending on the lowest temperature $\left(5^{\circ} \mathrm{C}\right)$, and potatoes are harvested from August to October of the same year. Among potato production areas, mid-late maturing cultivars (e.g., Yanshu No. 4, Atlantic, Jishu No. 1, and Summer) account for about 70\%, while early maturing cultivars (e.g., Favorita, Youjin, and Fujin) account for $30 \% 52$.

\section{Data}

\section{Climate data}

Climate data were obtained from the National Meteorological Information Center, China Meteorological Administration (http://data.cma.cn), including 51 national standard meteorological stations in Jilin Province (Fig.1). The meteorological data contain daily average temperature, daily maximum temperature, daily minimum temperature, daily sunshine hours, and daily precipitation during 1957-2018. According to the periods of potato sowing and harvesting in Jilin Province, the climate data between April 1 and September 31 each year were selected. To avoid the impact of extreme weather within a single year on the inter-annual climate change, we used five-year moving average values of climate data rather than single-year values to establish a geo-climate model using regression analysis and evaluated changes in suitable areas for potato cultivation under the influence of climate change.

\section{Topography data} (http://www.gscloud.cn). Through a series of processes such as adding X-Y axis, splicing, vector data layering, filtering, cropping, and resampling of raster data on the ArcGIS platform, digitized elevation model (DEM, $90 \mathrm{~m} \times 90 \mathrm{~m}$ ) maps were used to derivate layers such as longitude, latitude, slope, and aspect (Fig.1).

\section{Soil data}

Soil mechanical composition data (81 sampling sites) were derived from the National Science and Technology Infrastructure Platform (http://soil.geodata.cn) and soil physico-chemical property data (79 sampling sites) were provided by the Soil and Fertilizer General Station of Jilin Province (http://www.jltf.cn ). The sequence number of the occurrence layer is 1 , and the thickness is about $20-50 \mathrm{~cm}$, including contents of soil sand, silt, and clay, PH, and contents of nutrients such as organic matter (OM), quick-acting potassium (QAK), available nitrogen (AN), and available phosphorus (AP) (Fig.1; Tables S1-S2).

The soil data were rasterized using Kriging interpolation. First, the soil mechanical composition data were 
converted into spherical coordinates, and then ordinary Kriging interpolation was used to spatialize the soil mechanical composition data. Co-kriging interpolation was used to spatialize the soil physico-chemical property data. Due to limited soil samples and the lack of a continuous dataset in the study area, the soil data in 2018 were selected as a fixed background for the analysis.

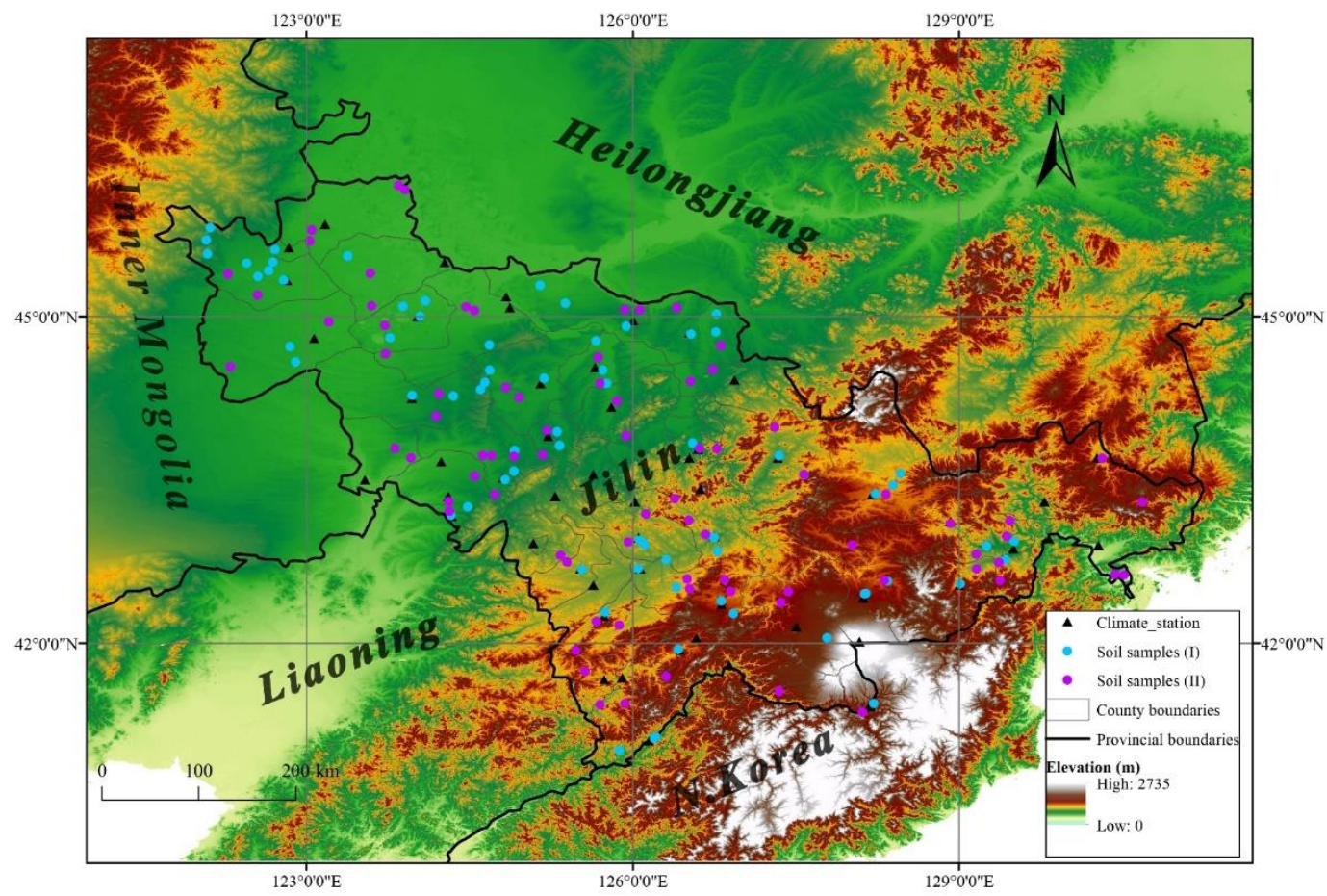

Figure 1. Spatial distribution of 51 meteorological stations and soil sampling sites in the study area. Soil data were divided into two categories. Soil samples (I): soil mechanical compositions, involving 81 sampling points; soil samples (II): soil physico-chemical properties, involving 79 sampling points.

\section{Analysis of climatic factors}

Usually, the development of potato has different requirements for light, heat, and water in each growth stage. We used average daily temperature during the growth period $\left(\mathrm{ADT} /{ }^{\circ} \mathrm{C}\right.$, mean of daily average temperature from April 1 st to September 30th) and active accumulated temperature $\geq 10^{\circ} \mathrm{C}\left(\mathrm{AAT} /{ }^{\circ} \mathrm{Cd}\right.$, sum of active accumulated temperature $\geq 10{ }^{\circ} \mathrm{C}$ from April 1st to September 30th) from 1961 to 2018 to reflect the temperature conditions of potato growth. ADT at 14$17{ }^{\circ} \mathrm{C}$ was evaluated as "Most suitable"; $10-14{ }^{\circ} \mathrm{C}$ or $17-20{ }^{\circ} \mathrm{C}$ as "Suitable"; 8-10 ${ }^{\circ} \mathrm{C}$ or $20-24{ }^{\circ} \mathrm{C}$ as "Sub-suitable"; < $17^{\circ} \mathrm{C}$ or $>24^{\circ} \mathrm{C}$ as "Not suitable" for potato growth in the study area. AAT for mid-late maturing varieties at 2,000$3,000{ }^{\circ} \mathrm{Cd}$ was evaluated as "Most suitable"; $1,500-2,000{ }^{\circ} \mathrm{Cd}$ or 3,000-6,000 ${ }^{\circ} \mathrm{Cd}$ as "Suitable"; $1,300-1,500{ }^{\circ} \mathrm{Cd}$ or $6000-8000{ }^{\circ} \mathrm{Cd}$ as "Sub-suitable"; $<1,300^{\circ} \mathrm{Cd}$ or $>8,000{ }^{\circ} \mathrm{Cd}$ as "Not suitable".

The average temperature in July (ATJ, mean of daily average temperature in July) and the day/night temperature difference from July to August $\left(\mathrm{DIF} /{ }^{\circ} \mathrm{C}\right.$, mean of the day/night temperature difference from July 1 st to August 31 st) are the key climatic factors for the expansion of potato chunks, which have significant correlation with the meteorological yield of potato ${ }^{53}$. ATJ at $16-20{ }^{\circ} \mathrm{C}$ was evaluated as "Most suitable"; $15-16{ }^{\circ} \mathrm{C}$ or $20-24{ }^{\circ} \mathrm{C}$ as "Suitable"; $12-15{ }^{\circ} \mathrm{C}$ or $24-28{ }^{\circ} \mathrm{C}$ as "Sub-suitable"; $<10{ }^{\circ} \mathrm{C}$ or $>28{ }^{\circ} \mathrm{C}$ as "Not suitable". DIF at $8-12^{\circ} \mathrm{C}$ was evaluated as "Most suitable"; 5$8{ }^{\circ} \mathrm{C}$ as "Suitable"; $2-5{ }^{\circ} \mathrm{C}$ as "Sub-suitable"; $<2{ }^{\circ} \mathrm{C}$ as "Not suitable" in the study area.

During the growth and development of potato, there is a great demand for water, especially from the budding stage to the swelling stage of potato growth, which are extremely sensitive to water supply. The total precipitation during the growth period (PP/mm, sum of the daily precipitation from April 1st to September 30th) at 700-900 mm was evaluated 
as "Most suitable"; 600-700 mm or 900-1,200 mm as "Suitable"; 500-600 mm or 1,200-1,500 mm as "Sub-suitable"; < $500 \mathrm{~mm}$ or $>1,500 \mathrm{~mm}$ as "Not suitable" in the study area.

Short daylight and appropriate high temperature during the seedling stage are beneficial to promote potato root development, forming strong seedlings and increasing potato formation. The total sunshine duration during potato growth (SD/hours, sum of the daily sunshine duration from April 1st to September 30th) at 900-1,200 h was evaluated as "Most suitable"; 700-900 h or 1,200-1,500 h as "Suitable"; 400-700 h or 1,500-1,800 h as "Sub-suitable"; < $400 \mathrm{~h}$ or $>1,800 \mathrm{~h}$ as "Not suitable".

\section{Methods}

First, climatic factors were simulated using geo-climate models. Then, the AHP-PCA model was employed for suitability evaluation, and the satellite-based gridded environmental data were applied for suitability mapping. Finally, the degree of changes in climatic factors and suitable geographic ranges was calculated. These data were interpolated into the surface grid data with a spatial resolution of $0.03^{\circ} \times 0.03^{\circ}(\sim 3 \mathrm{~km} \times 3 \mathrm{~km})^{54,55}$. All maps and statistical analyses were generated using ArcGIS 10.4.1 ${ }^{56}$ and R 3.6.3 ${ }^{57}$.

\section{Geo-climate model building}

Topographic factors such as longitude, latitude, and altitude dominate the distribution of climate factors, and directly affect the solar radiation budget and atmospheric circulation, which makes the climate resources to demonstrate obvious spatial differences in both vertical and horizontal directions ${ }^{58,59}$. Based on the meteorological data and geographic information of each meteorological station, we established geo-climate models and used them to calculate the climate distribution of the study area. And the difference between the highest temperature and the lowest temperature from July 1 st to August 31 st was used to calculate the grid layer of DIF. The relationship between climate zoning indicators and geographic factors is expressed as follows:

$$
F=f(\lambda, \varphi, h)+\varepsilon
$$

where, $F$ is the simulated value of grid point of the climate zoning index; $\lambda$, $\varphi$, and $h$ represent longitude $\left(^{\circ}\right)$, latitude $\left(^{\circ}\right)$, and altitude $(\mathrm{m})$, respectively; $f(\lambda, \varphi, h)$ is called climatological equation of regionalization index; and $\varepsilon$ is the influence of local small topography and random factors on climate (i.e., comprehensive geographical residual term).

Residual correction : Affected by local topography and random factors, the variation of climatic factors is random, which will cause errors in the calculation of geo-climate models. Therefore, the inverse distance weight (IDW) routine in ArcGIS was used to derive the simulated value of the comprehensive geographical residual term $\varepsilon$ raster $^{60}$. The interpolation calculation formula is:

$$
\varepsilon=\sum_{i=1}^{n} \frac{\varepsilon_{i}}{d_{i}^{k}} / \sum_{i=1}^{n} d_{i}^{k}
$$

where, $\varepsilon$ is the simulated value of the grid point of the residual term of climatic factors; $n$ is the number of meteorological stations; $\varepsilon_{i}$ is the residual value of the climate factor of the $i$-th meteorological station; $d_{i}$ is the Euclidean distance between the grid point and the $i$-th meteorological station; $k$ is the power of the distance.

\section{AHP-PCA and GIS based suitability analysis for potato cultivation}

The suitability map for potato cultivation was generated based on identified criteria that are relevant to the climatic, soil environmental, and geophysical conditions considered. Details of the data analysis procedure, model application, and suitability classification are described as follows.

\section{- $\quad$ AHP-PCA model}

AHP is a multi-criterion decision-based approach developed for analyzing complex decisions involving multiple 
criteria $^{39,61-62}$. PCA is a multivariate statistical data analysis technique that combines all input variables using a linear combination into a number of principal components that retain the most variance within the original data to identify possible patterns or clusters between objects and variables. In this study, we used AHP to calculate the weight of each zoning indicator in the evaluation index system ${ }^{63-64}$, and then, we explored the comprehensive relationship of suitability evaluation factors using the grid calculator and PCA tool on the ArcGIS platform. The variance of the weighted original data becomes larger, resulting to more scientific and reasonable evaluation results. In summary, the proposed approach is achieved as follows:

Step 1: The weight of each index was calculated by using AHP and consistency test;

Step 2: The indicators were standardized using the Z-Score method;

Step 3: The weights calculated in Step 1 were loaded onto the standardized indicators;

Step 4: A standardized matrix was built and the correlation coefficient matrix was calculated;

Step 5: The principal components was filtered and determined;

Step 6: The score for each principal component was calculated;

Step 7: A comprehensive score for all indicators was obtained.

\section{- Establishment of indicator system and calculation of weight}

The assessment of climate change impacting suitability of potato cultivation has multiple objectives and levels. This paper combined comprehensive and hierarchical principles, relevant literature reviews ${ }^{39,40,41,65}$, expert opinions, and characteristics of potato cultivation in Jilin Province to establish an index system for evaluation of ecological environment impact, including 18 evaluation indicators: ADT $\left({ }^{\circ} \mathrm{C}\right), \operatorname{AAT}\left({ }^{\circ} \mathrm{Cd}\right), \operatorname{PP}(\mathrm{mm}), \operatorname{SD}(\mathrm{h}), \operatorname{ATJ}\left({ }^{\circ} \mathrm{C}\right), \operatorname{DIF}\left({ }^{\circ} \mathrm{C}\right)$, elevation (m), slope $\left(^{\circ}\right)$, aspect $\left(^{\circ}\right)$, hill shade, sand $(\%)$, silt $(\%)$, clay $(\%), \mathrm{OM}(\mathrm{g} / \mathrm{kg}), \mathrm{PH}, \mathrm{QAK}(\mathrm{mg} / \mathrm{kg}), \mathrm{AN}(\mathrm{mg} / \mathrm{kg})$, and AP $(\mathrm{mg} / \mathrm{kg})$. These indicators were classified into three categories: climatic conditions, soil environments, and topography (Table 1).

The weight of each evaluation indicator was determined by AHP. According to relevant literatures and expert opinions, we established a judgment matrix for these evaluation indicators. Pairwise comparison was used for obtaining the relative importance score between different indicators. The consistency of pairwise importance scales is one of the important measurements for successful decision-making by AHP, which could be checked using consistency ratio (CR). If $\mathrm{CR}<0.10$, the degree of consistency is satisfactory. Otherwise, $\mathrm{CR}>0.10$ indicates an inconsistency ${ }^{60,66}$ (Table 1$)$.

Table 1. Weights of all criteria used for estimating suitability of potato cultivation in the study area

\begin{tabular}{|c|c|c|c|c|c|c|}
\hline Goal & Main criteria & Weight & $\mathbf{C R}^{\mathrm{a}}$ & Sub-criteria $^{b}$ & Weight & $\mathbf{C R}^{\mathrm{a}}$ \\
\hline \multirow{13}{*}{$\begin{array}{l}\text { Suitability } \\
\text { of } \\
\text { potato } \\
\text { cultivation }\end{array}$} & \multirow{6}{*}{ Climate } & \multirow{6}{*}{0.53} & \multirow[t]{13}{*}{0.001} & $\operatorname{AAT}\left({ }^{\circ} \mathrm{Cd}\right)$ & 0.37 & \multirow[t]{6}{*}{0.007} \\
\hline & & & & $\operatorname{DIF}\left({ }^{\circ} \mathrm{C}\right)$ & 0.24 & \\
\hline & & & & $\operatorname{ATJ}\left({ }^{\circ} \mathrm{C}\right)$ & 0.17 & \\
\hline & & & & $\mathrm{ADT}\left({ }^{\circ} \mathrm{C}\right)$ & 0.10 & \\
\hline & & & & $\mathrm{SD}(\mathrm{h})$ & 0.07 & \\
\hline & & & & $\mathrm{PP}(\mathrm{mm})$ & 0.05 & \\
\hline & \multirow{3}{*}{$\begin{array}{l}\text { Soil mechanical } \\
\text { composition }\end{array}$} & \multirow{3}{*}{0.18} & & Sand $(\%)$ & 0.59 & \multirow[t]{3}{*}{0.005} \\
\hline & & & & Silt (\%) & 0.28 & \\
\hline & & & & Clay $(\%)$ & 0.13 & \\
\hline & \multirow{4}{*}{$\begin{array}{l}\text { Soil } \\
\text { physico- } \\
\text { chemical }\end{array}$} & \multirow{4}{*}{0.18} & & $\mathrm{PH}$ & 0.27 & \multirow[t]{4}{*}{0.001} \\
\hline & & & & $\mathrm{OM}(\mathrm{g} / \mathrm{kg})$ & 0.36 & \\
\hline & & & & QAK $(\mathrm{mg} / \mathrm{kg})$ & 0.17 & \\
\hline & & & & $\mathrm{AN}(\mathrm{mg} / \mathrm{kg})$ & 0.12 & \\
\hline
\end{tabular}




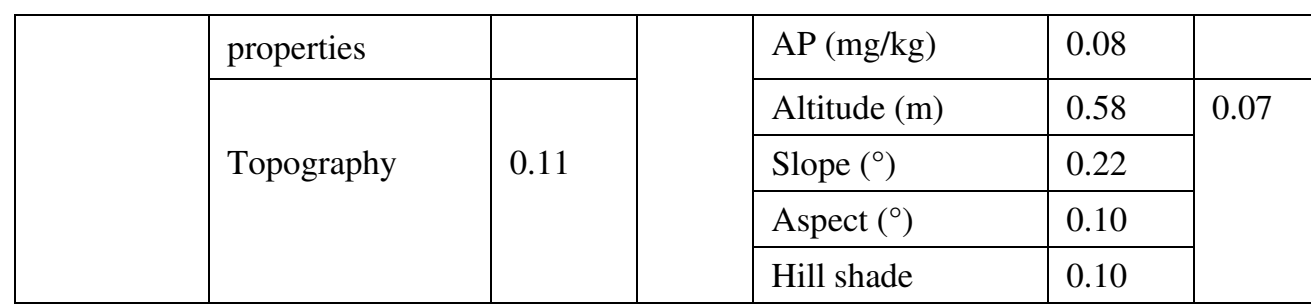

a $\mathrm{CR}$ (consistency ratio) $<0.1$ means that the pairwise comparison matrix has an acceptable consistency. b ADT: average daily temperature during the growth period $\left({ }^{\circ} \mathrm{C}\right)$; AAT: sum of active accumulated temperature $\geq 10^{\circ} \mathrm{C}$ $\left({ }^{\circ} \mathrm{Cd}\right)$; PP: total precipitation during the growth period $(\mathrm{mm})$; SD: total sunshine duration during the growth period $(\mathrm{h})$; ATJ: average temperature in July $\left({ }^{\circ} \mathrm{C}\right)$; DIF: the day/night temperature difference from July to August $\left({ }^{\circ} \mathrm{C}\right)$; OM: soil organic matter (g/kg); QAK: soil quick-acting potassium (mg/kg); AN: soil available nitrogen (mg/kg); AP: soil available phosphorus $(\mathrm{mg} / \mathrm{kg})$.

- Classification and mapping for suitability of potato cultivation

In this paper, the natural breakpoint method in ArcGIS was employed to classify lands of the study area in terms of cultivation suitability. The study area was delineated into 4 zones: zone 1 (Not suitable), zone 2 (Sub-suitable), zone 3 (Suitable), and zone 4 (Most suitable) (Table 2).

After normalizing all indicators, the cultivation suitability index was established as follows:

$I=\sum_{i}^{n} W_{i} X_{i}$

where $I$ is the suitability index for comprehensive evaluation, $W_{i}$ is the weight of the indicator, $X_{i}$ is the value after dimensionless treatment of the indicator, $i$ is the comprehensive evaluation value of topography, climatic conditions, and soil environments. During the calculation, the larger the topography value, the greater the negative impact on cultivation suitability; it was converted into a negative value for the calculation. Meanwhile, the greater the $\mathrm{pH}$ value is, the more unfavorable the comprehensive evaluation of soil will be; the PH value was therefore inversed for the calculation.

Table 2. Dimensionless grading of evaluation values of potato cultivation suitability

\begin{tabular}{|l|l|l|l|l|}
\hline Cultivation suitability & Not suitable & Sub-suitable & Suitable & Most suitable \\
\hline Evaluation value $I$ & $<0.54$ & $0.54-0.78$ & $0.78-0.88$ & $>0.88$ \\
\hline
\end{tabular}

\section{Trends and fluctuations in changes of climatic factors and suitable areas}

The fluctuations of various climatic factors over the past 58 years were analyzed by coefficient of variation (CV), which was calculated as $\mathrm{CV}=($ standard deviation $/$ mean $) \times 100 \%$. Temporal trends in changes of climatic factors and suitable areas were calculated using ordinary least squares linear regression on annual data from 1961 to 2018 . Among them, the trend in suitable area changes was calculated based on each grid. The significance of trends was estimated following a method that considers the temporal autocorrelation by reducing the effective sample size of the time series ${ }^{67}$. And the significance of temporal trends was tested at $P<0.1^{68}$.

\section{Results}

\section{Inter-annual variation of climatic factors}

From 1961 to 2018 (April to September), various climatic factors showed a certain change over time in Jilin Province. Within this period, AAT (mean $=2,891.90^{\circ} \mathrm{Cd}$ ) ranged from $2,550{ }^{\circ} \mathrm{Cd}$ to $3,150{ }^{\circ} \mathrm{Cd}$, showing a large fluctuation range $\left(\mathrm{CV}_{1}=3.45 \%\right)$ and an obvious rising trend $(P<0.1)$ at an increasing rate of $49.27{ }^{\circ} \mathrm{Cd} \mathrm{decade}^{-1}\left(\mathrm{R}^{2}=0.70, P<0.01\right)$. $\operatorname{ADT}\left(\right.$ mean $\left.=16.81{ }^{\circ} \mathrm{C}\right)$ was between $15.30{ }^{\circ} \mathrm{C}$ and $18.10{ }^{\circ} \mathrm{C}$ and with a small fluctuation range $\left(\mathrm{CV}_{2}=2.67 \%\right)$, 
exhibiting a significant upward trend $(P<0.1)$, with an increasing rate of $0.22{ }^{\circ} \mathrm{C}$ decade ${ }^{-1}\left(\mathrm{R}^{2}=0.68, P<0.01\right)$. ATJ $\left(\right.$ mean $\left.=22.42{ }^{\circ} \mathrm{C}\right)$ was between $20.50{ }^{\circ} \mathrm{C}$ to $24.50{ }^{\circ} \mathrm{C}$, with a relatively small fluctuation range $\left(\mathrm{CV}_{3}=2.33 \%\right)$; DIF $\left(\right.$ mean $\left.=9.77{ }^{\circ} \mathrm{C}\right)$ ranged from $8{ }^{\circ} \mathrm{C}$ to $11^{\circ} \mathrm{C}$, with a large fluctuation range $\left(\mathrm{CV}_{4}=3.85 \%\right)$; however, neither of them showed a significant trend $(P>0.1)$. PP (mean $=507.37 \mathrm{~mm})$ was between $380 \mathrm{~mm}$ and $620 \mathrm{~mm}$, which fluctuated greatly $\left(\mathrm{CV}_{5}=7.32 \%\right)$ but no significance was observed in the change trend $(P>0.1)$. SD $(\mathrm{mean}=1,376.52 \mathrm{~h})$ ranged from $1140 \mathrm{~h}$ to $1540 \mathrm{~h}$, with a large fluctuation $\left(\mathrm{CV}_{6}=3.81 \%\right)$ and a significant decrease $(P<0.1)$ at a rate of $25.31 \mathrm{~h}$ decade $^{-1}\left(\mathrm{R}^{2}=0.66, P<0.01\right)$ (Fig.2). It can be seen that the fluctuation range of precipitation was far greater than that of temperature and sunshine $\left(\mathrm{CV}_{5}>\mathrm{CV}_{6}>\mathrm{CV}_{4}>\mathrm{CV}_{1}>\mathrm{CV}_{2}>\mathrm{CV}_{3}\right)$.

The comprehensive evaluation value $($ mean $=0.43)$ of climatic suitability for potato cultivation in Jilin Province fluctuated greatly $(\mathrm{CV}=37.05 \%)$. Splitting the period of 1961-2018 into three distinct intervals was achieved by inspecting the linear trend of comprehensive values. It was found that the value of climatic suitability fluctuated slightly from 1961 to $1989(\mathrm{CV}=24.06 \%)$ and showed no significance in change trend $(P>0.1)$. From 1990 to 2001 , it fluctuated greatly $(\mathrm{CV}=49.04 \%)$ and presented a steep upward trend $(P<0.05)$. From 2002 to 2018 , the fluctuation was small $(\mathrm{CV}=16.68 \%)$, which decreased slowly at first and then increased (Fig.2).

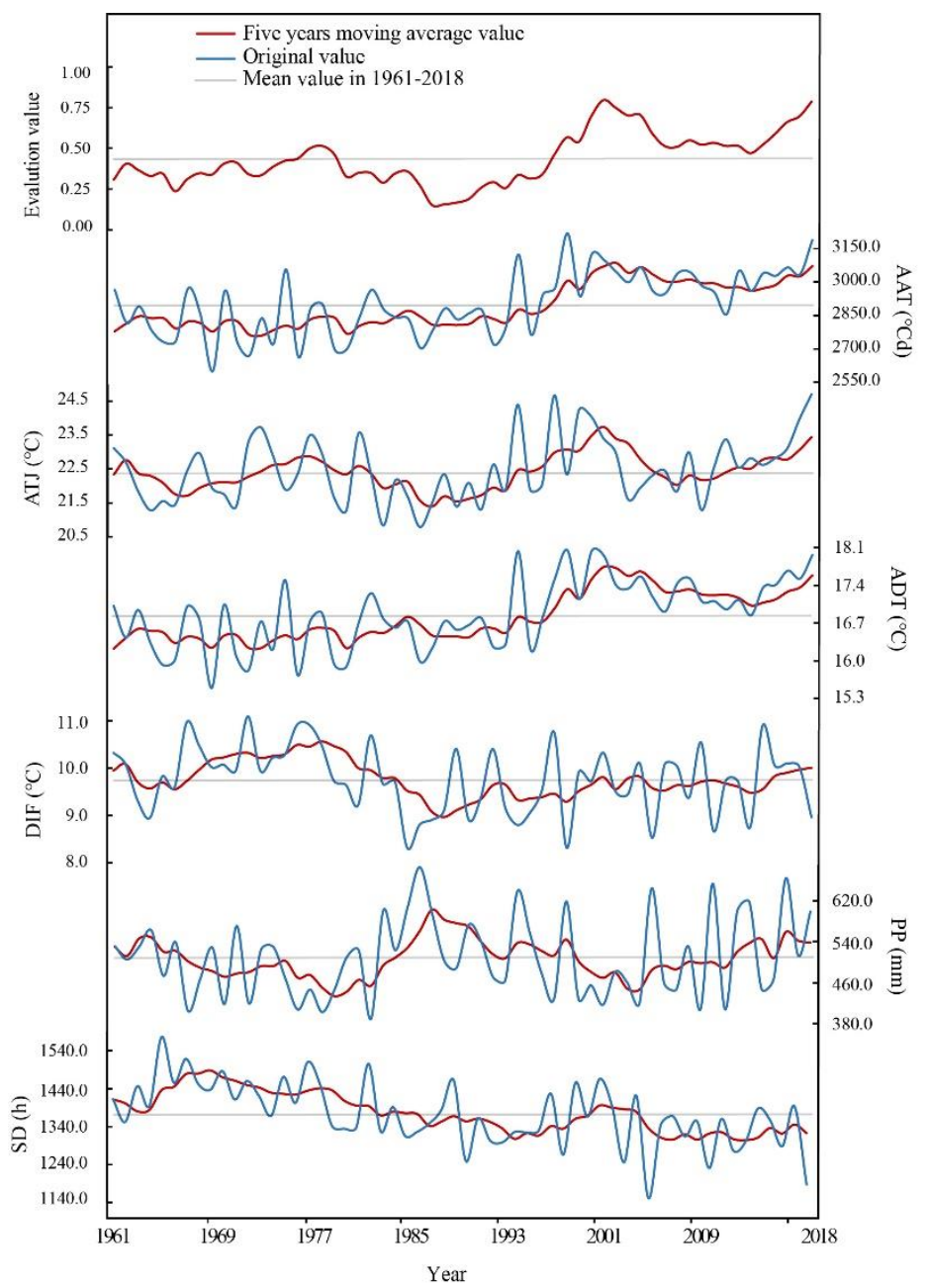

Figure 2. Inter-annual variation trends of climatic factors and evaluation values in the study area from 1961 to 2018. ADT: average daily temperature during the growth period $\left({ }^{\circ} \mathrm{C}\right)$; AAT: sum of active accumulated temperature $\geq 10^{\circ} \mathrm{C}$ $\left({ }^{\circ} \mathrm{Cd}\right)$; PP: total precipitation during the growth period $(\mathrm{mm})$; SD: total sunshine duration during the growth period $(\mathrm{h})$; ATJ: average temperature in July $\left({ }^{\circ} \mathrm{C}\right)$; DIF: the day/night temperature difference from July to August $\left({ }^{\circ} \mathrm{C}\right)$. 


\section{Climate inclination rates varied across the study area}

During the period of 1961-2018, within Jilin Province, the values of both sunshine and temperature were greater in the western plains than in the eastern mountainous regions while the precipitation gradually decreased from the southeast to the northwest. AAT ranged from 910 to $3,390{ }^{\circ} \mathrm{Cd}$ in the study area, which showed an overall increasing trend, with the tendency rate gradually decreased from the west to the east (Fig.3a). The area of regions with an AAT tendency rate between $75.71-95.34,59.71-75.71$, and $26.30-59.71{ }^{\circ} \mathrm{Cd}$ decade ${ }^{-1}$ accounted for $44.54 \%, 40.68 \%$, and $14.78 \%$ of the total area, respectively. There were $96.96 \%$ area of Jilin Province passed the significance test $(P<0.1$; Fig.S1a). ADT was between $6.5-24.5{ }^{\circ} \mathrm{C}$, showing an increasing trend and accounting for $93.36 \%$ of the total area (Fig.3b). The tendency rate of ADT was greater in the northwest than in the southeast. The area of regions with an ADT tendency rate between $0-0.18,0.18-0.46$, and $-0.14-0{ }^{\circ} \mathrm{C}$ decade $^{-1}$ accounted for $52.85 \%, 40.50 \%$, and $6.64 \%$ of the total area, respectively. There were $50.99 \%$ area of Jilin Province passed the significance test $(P<0.1$; Fig.S1b). DIF was between 7.0-16.0 ${ }^{\circ} \mathrm{C}$ in Jilin Province, which showed a decreasing trend in $88.71 \%$ of the regions, with a climate trend slope range of $-0.45-0{ }^{\circ} \mathrm{C}$ decade $^{-1}$. The rest of the study area possessed a DIF tendency rate of $0-0.17^{\circ} \mathrm{C} \mathrm{decade}{ }^{-1}$ (Fig.3c). There were $20.25 \%$ area of the study area passed the significance test $(P<0.1$; Fig.S1c). SD was in the range of 1035 $1725 \mathrm{~h}$, showing a significant downward trend in most of the study area (Fig.3d). The area of regions with a SD tendency rate between $-34.03-0$ and $-(61.13-34.03) \mathrm{h}$ decade $^{-1}$ accounted for $77.77 \%$ and $21.76 \%$ of the total area. There were $76.04 \%$ area of Jilin Province passed the significance test $\left(P<0.1\right.$; Fig.S1e). However, ATJ was between $14.5-25.5^{\circ} \mathrm{C}$ and PP was between 350-1,020 mm. The tendency rates of both ATJ and PP showed no significance in inter-annual changes $(P>0.1$; Fig.S1d, f) during 1961-2018.
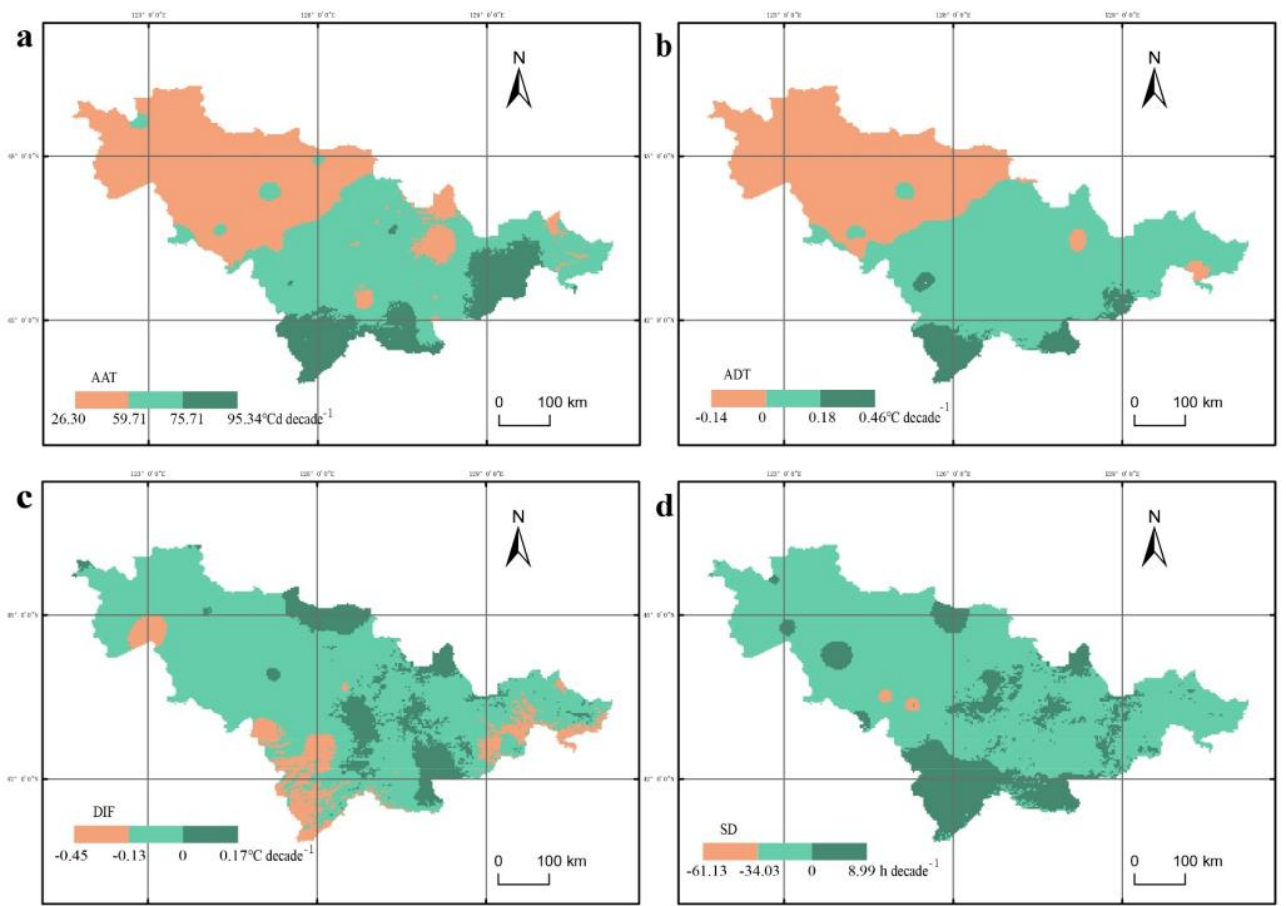

Figure 3. Maps for spatial distribution of climate inclination rates varied across Jilin Province from 1961 to 2018 . (a) The active accumulated temperature of $\geq 10^{\circ} \mathrm{C}$. (b) Average daily temperature during the growth period. (c) The average day/night temperature difference from July to August. (d) Sunshine durations.

\section{Trends in climate-driven suitability zonation varied across the study area}

From 1961 to 1988, evident changes were observed in the suitable areas for potato cultivation, of which approximately $80.99 \%$ showed significance (Fig.4a). The results showed that $1.21 \%$ area of Jilin Province suitable for potato 
cultivation were mainly distributed in the marginal zone to the southeast, with a negative growth trend $(-3.94 \%-0$ decade $\left.^{-1}, P<0.1\right)$. The $28.52 \%$ area of Jilin Province suitable for potato cultivation were mainly located in the central and eastern parts, showing a slow growth trend $\left(0-2 \%\right.$ decade $\left.^{-1}, P<0.1\right)$. The $51.27 \%$ area of Jilin Province suitable for potato cultivation occurred mainly in the northwestern regions, exhibiting a significant increasing trend $(2 \%-4.86 \%$ decade $\left.^{-1}, P<0.01\right)$.

From 1988 to 2018, the degree of changes in suitable areas was relatively small, and $34.26 \%$ of the areas passed the significance test (Fig.4b). Our results show that 7.36\% area of Jilin Province suitable for potato cultivation were mainly distributed in the southeastern marginal zone, showing a slow negative growth trend $\left(-2.05 \%-0\right.$ decade ${ }^{-1}, P<$ $0.1)$. The $26.90 \%$ area of Jilin Province showing a slow increasing trend $\left(0-1.77 \%\right.$ decade $\left.^{-1}, P<0.1\right)$ were distributed in the northwest.

During the period of 1961-2018, the suitable areas for potato cultivation in Jilin Province changed significantly. About $72.36 \%$ of the areas passed the significance test (Fig.4c). We found that $9.78 \%$ area of Jilin Province suitable for potato cultivation were mainly distributed in the marginal zone to the southeast, showing a slow negative growth trend $\left(-1.35 \%-0\right.$ decade $\left.^{-1}, P<0.1\right)$. The $30.63 \%$ area of Jilin Province suitable for potato cultivation were mainly located in the central and eastern regions, with a slow growth trend $\left(0-1 \%\right.$ decade $\left.^{-1}, P<0.1\right)$. The potato cultivation suitability showing a relatively rapid growth trend in $31.95 \%\left(1-2 \%\right.$ decade $\left.^{-1}, P<0.01\right)$ and $0.03 \%\left(2-4.86 \%\right.$ decade $\left.^{-1}, P<0.01\right)$ area of Jilin Province, respectively, mainly occurred in the northwestern regions.

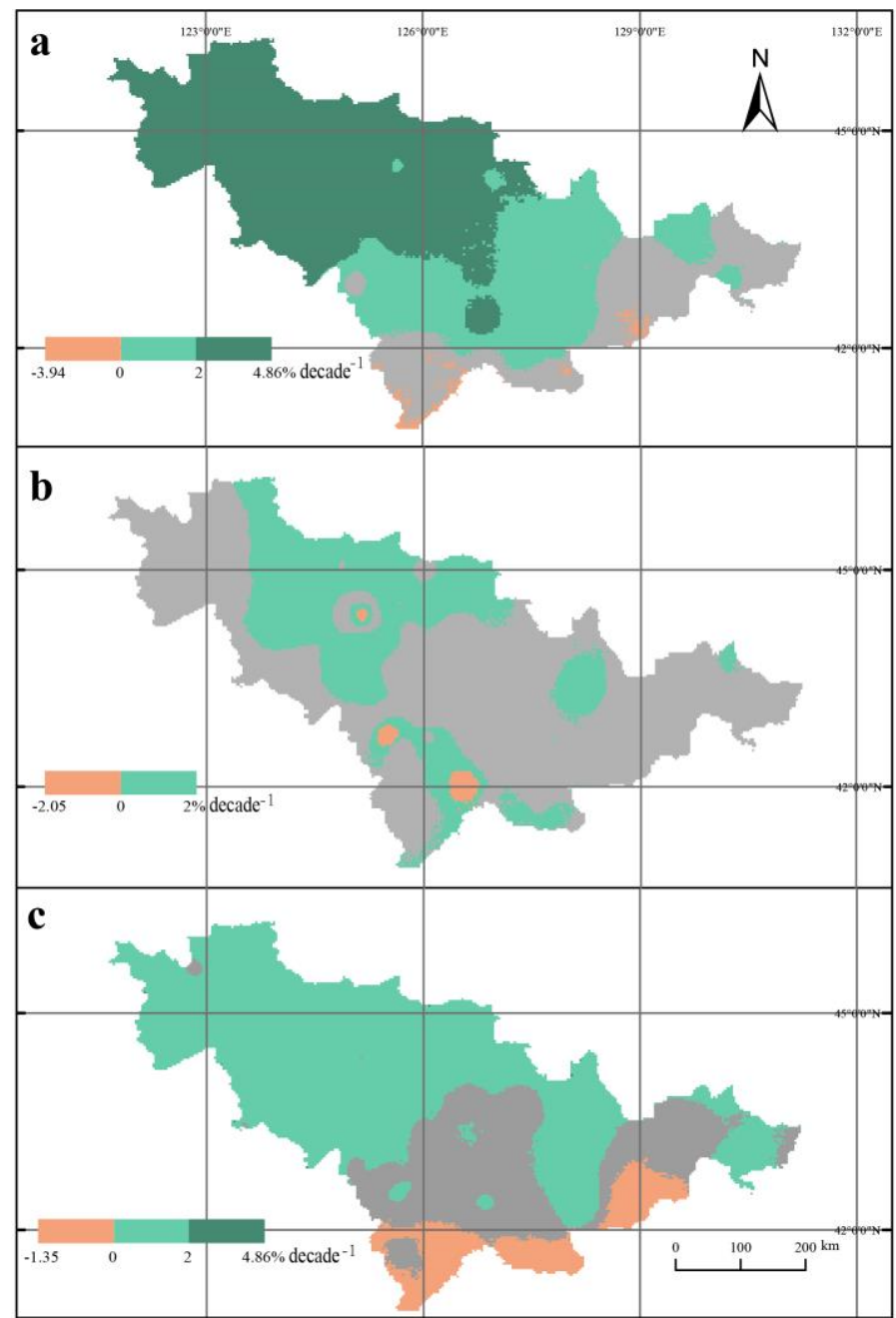

Figure 4. Maps for trends in climate-driven suitability zonation across Jilin Province from 1957 to 2018. (a) 1961 - 
1988; (b) 1988-2018; (c) 1961-2018. The grey shades in (a-c) indicate the regions where trends in area change of suitability zonation failed the significance test $(\mathrm{P}>0.1)$.

\section{Temporal and spatial distributions of suitable areas for potato cultivation}

334 From the perspective of spatial distribution, the "Most suitable" and "Suitable" areas exhibited a trend towards northwest, while the "Sub-suitable" area tended to shrink to the eastern mountainous areas. According to Fig.2, the comprehensive evaluation value in 1988 was the lowest during the past 60 years. Therefore, the three periods, including 1961-2018, 1961-1988, and 1988-2018, were selected to compare the changes in the suitable areas. The area of "Most suitable" areas increased by $25.40 \times 1,000 \mathrm{~km}^{2}$ from 1961 to 1988 (Fig.5a,b) and by $2.11 \times 1,000 \mathrm{~km}^{2}$ from 1988 to 2018 (Fig.5b,c), with a $12.42 \%$ decrease in the percentage increase in area. The area of "Suitable" areas increased by $16.17 \times 1,000 \mathrm{~km}^{2}$ from 1961 to 1988 (Fig.5a,b) and by $1.10 \times 1,000 \mathrm{~km}^{2}$ from 1988 to 2018 (Fig.5b,c), with a 8.04\% decrease in the percentage increase in area. The area of "Sub-suitable" areas decreased by $41.65 \times 1,000 \mathrm{~km}^{2}$ from 1961 to 1988 (Fig.5a,b) and by $1.77 \times 1,000 \mathrm{~km}^{2}$ from 1988 to 2018 (Fig.5b,c), with a $21.28 \%$ decreased in the area ratio. The area of "Not suitable" areas increased by $0.08 \times 1,000 \mathrm{~km}^{2}$ from 1961 to 1988 (Fig.5a,b) and decreased by $1.43 \times$ $1,000 \mathrm{~km}^{2}$ from 1988 to 2018 (Fig.5b,c), with little change in the study area.

In general, from 1961 to 2018 (Fig.5a-c), the "Most suitable" areas are mainly distributed in the mountainous areas of the central and eastern regions of Jilin Province, where the climatic conditions (see Fig.S2-S4) are conducive to potato tuber growth and starch accumulation. The "Suitable" areas are mainly distributed in the central and western plains, where the climatic conditions are suitable for potato cultivation and growth. The "Sub-suitable" areas are mainly distributed in low-altitude mountainous areas in the east, where precipitation conditions (see Fig.S2f, S3f, S4f) are favorable for potato tuber enlargement, and the overall climatic conditions are suitable for potato growth. The "Not suitable" areas are located in the eastern high altitudes, where the distributions of water, heat, and light resources are 


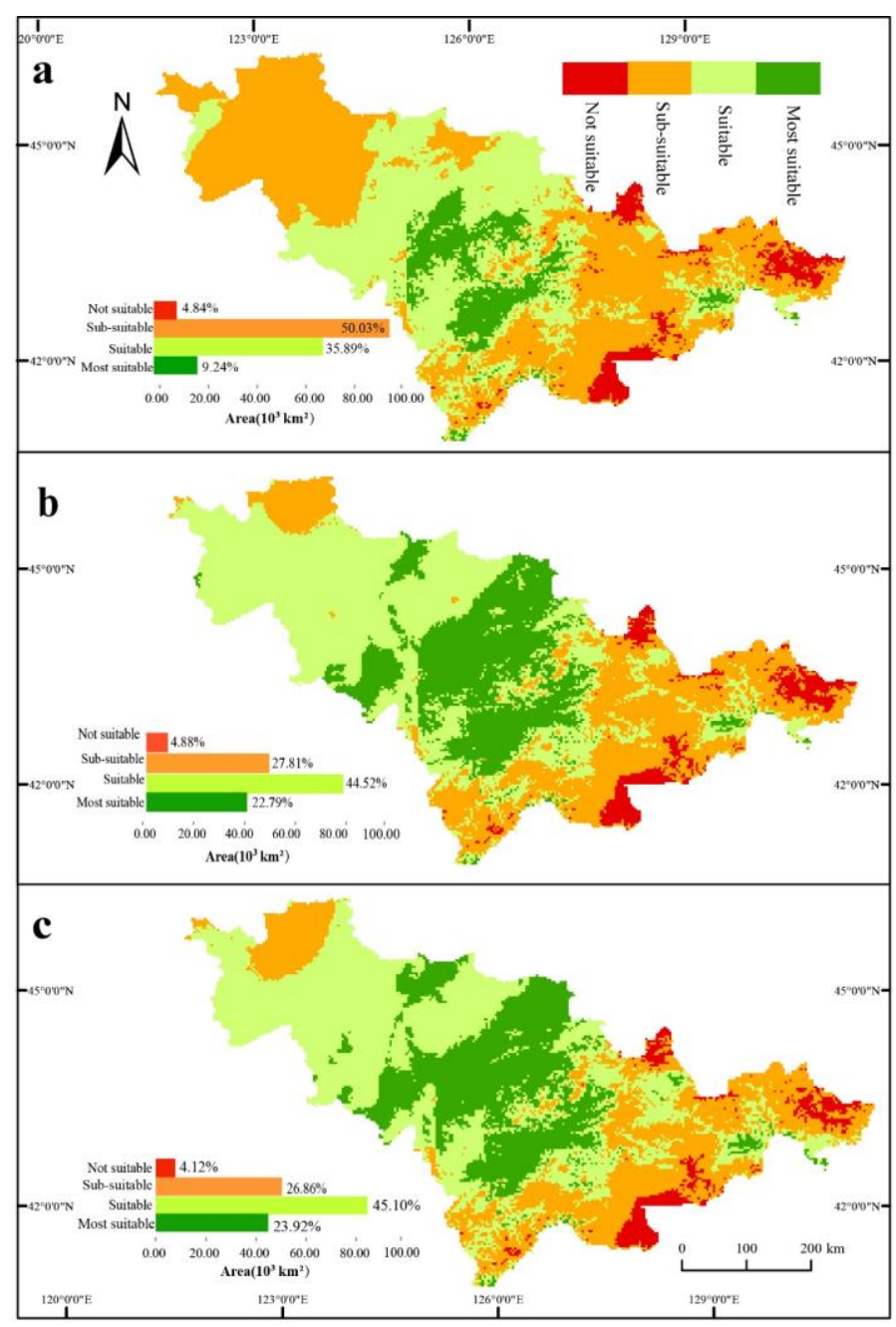

Figure 5. Maps for spatio-temporal changes in the distribution of suitability zonation for potato cultivation in Jilin Province. (a) In 1961, the areas of "Not suitable", "Sub-suitable", "Suitable", and "Most suitable" areas were $9.08 \times$ $10^{3}, 93.76 \times 10^{3}, 67.25 \times 10^{3}$, and $17.31 \times 10^{3} \mathrm{~km}^{2}$, respectively. (b) In 1988, the areas of "Not suitable", "Sub-suitable", "Suitable", and "Most suitable" areas were $9.15 \times 10^{3}, 52.11 \times 10^{3}, 83.42 \times 10^{3}$, and $42.71 \times 10^{3} \mathrm{~km}^{2}$, respectively. (c) In 2018, the areas of "Not suitable", "Sub-suitable", "Suitable", and "Most suitable" areas were $7.72 \times 10^{3}, 50.33 \times 10^{3}$, $84.53 \times 10^{3}$, and $44.82 \times 10^{3} \mathrm{~km}^{2}$, respectively.

\section{Variation in the area of suitability zonation for potato cultivation}

The suitable areas for potato cultivation in Jilin Province from 1961 to 2018 were analyzed annually, and the annual change of suitable areas was obtained (Fig.6).

We found that the maximum area of "Most suitable" areas was $49.94 \times 1,000 \mathrm{~km}^{2}$ in 2015, and the minimum was $16.50 \times 1,000 \mathrm{~km}^{2}$ in 1962 . The area of "Most suitable" areas increased significantly $(P<0.01)$, with an increasing rate of $0.37 \times 1,000 \mathrm{~km}^{2}$ decade $^{-1}\left(\mathrm{R}^{2}=0.58\right)$ during the past 60 years. From the $1960 \mathrm{~s}$ to the late $1970 \mathrm{~s}$, the area of "Most suitable" areas increased significantly $(P<0.0001)$, with an increasing rate of $0.85 \times 1,000 \mathrm{~km}^{2} \mathrm{decade}^{-1}\left(\mathrm{R}^{2}=0.76\right)$. From the early 1980 s to the mid-1990s, the area exhibited a significant downward trend $(P<0.001)$, with a decreasing rate of $0.54 \times 1,000 \mathrm{~km}^{2} \mathrm{decade}^{-1}\left(\mathrm{R}^{2}=0.51\right)$. From the late 1990s to 2018, the area of "Most suitable" areas increased slowly $(P<0.05)$, with an increasing rate of $0.40 \times 1,000 \mathrm{~km}^{2} \mathrm{decade}^{-1}\left(\mathrm{R}^{2}=0.26\right)$.

The area of "Suitable" areas showed a significant increasing trend $(P<0.1)$, with a maximum value of $90.00 \times$ $1,000 \mathrm{~km}^{2}$ in 1982, a minimum value of $64.05 \times 1,000 \mathrm{~km}^{2}$ in 1964 , and an increasing rate over the past 60 years of 0.20 
$\times 1,000 \mathrm{~km}^{2}$ decade ${ }^{-1}\left(\mathrm{R}^{2}=0.28\right)$. From the $1960 \mathrm{~s}$ to the late $1970 \mathrm{~s}$, the area of "Suitable" areas increased significantly $(P<0.05)$, with an increasing rate of $0.92 \times 1,000 \mathrm{~km}^{2}$ decade ${ }^{-1}\left(\mathrm{R}^{2}=0.66\right)$. From the early $1980 \mathrm{~s}$ to the mid-1990s, the area of "Sub-suitable" areas showed a sharp downward trend $(P<0.0001)$ at a rate of $0.92 \times 1,000 \mathrm{~km}^{2} \mathrm{decade}^{-1}$ $\left(\mathrm{R}^{2}=0.61\right)$. From the late 1990 s to 2018 , there was no significant change in the area of "Suitable" areas $(P>0.1)$.

The area of "Sub-suitable" areas showed a significant decline $(P<0.05)$ at a rate of $0.58 \times 1,000 \mathrm{~km}^{2} \mathrm{decade}^{-1}\left(\mathrm{R}^{2}\right.$ $=0.53$ ) in the past 60 years. Its maximum value was $97.17 \times 1,000 \mathrm{~km}^{2}$ in 1962 , and minimum value was $45.13 \times 1,000$ $\mathrm{km}^{2}$ in 1982 . From the 1960 s to the late 1970 s, there was a significant increase in the area of "Sub-suitable" areas $(P<$ $0.01)$, with an increasing rate of $1.77 \times 1,000 \mathrm{~km}^{2}$ decade $^{-1}\left(\mathrm{R}^{2}=0.83\right)$. From the early $1980 \mathrm{~s}$ to the mid-1990s, the area of "Sub-suitable" areas in Jilin Province increased significantly $(P<0.01)$, with an increasing rate of $1.45 \times 1,000 \mathrm{~km}^{2}$ decade $^{-1}\left(\mathrm{R}^{2}=0.62\right)$; while from the late 1990 s to 2018 , it slowly decreased $(P<0.1)$ at a rate of $0.43 \times 1,000 \mathrm{~km}^{2}$ decade $^{-1}\left(\mathrm{R}^{2}=0.22\right)$.

There was no significant change in the area of "Not suitable" areas. The maximum was $12.43 \times 1,000 \mathrm{~km}^{2}$ in 2015 , and the minimum was $7.44 \times 1,000 \mathrm{~km}^{2}$ in $1962(P>0.1)$.

Overall, the proportion of the suitable areas for potato cultivation in Jilin Province from 1961 to 2018 was "Suitable" areas > "Sub-suitable" areas > "Most suitable" areas > "Not suitable" areas. Among them, the average values of "Most suitable", "Suitable", "Sub-suitable", and "Not suitable" areas were $35.42 \times 1,000,79.91 \times 1,000,63.10 \times 1,000$, and $8.97 \times 1,000 \mathrm{~km}^{2}$, respectively. In the past 58 years, the area of "Most suitable" areas for potato cultivation has increased more sharply than that of "Suitable" areas, and both of them showed a significant decline from the early 1980s to the 1990 s, with a more significant decrease observed in the area of "Suitable" areas. However, the change in the area of "Sub-suitable" areas showed an opposite trend to that of the aforementioned two.

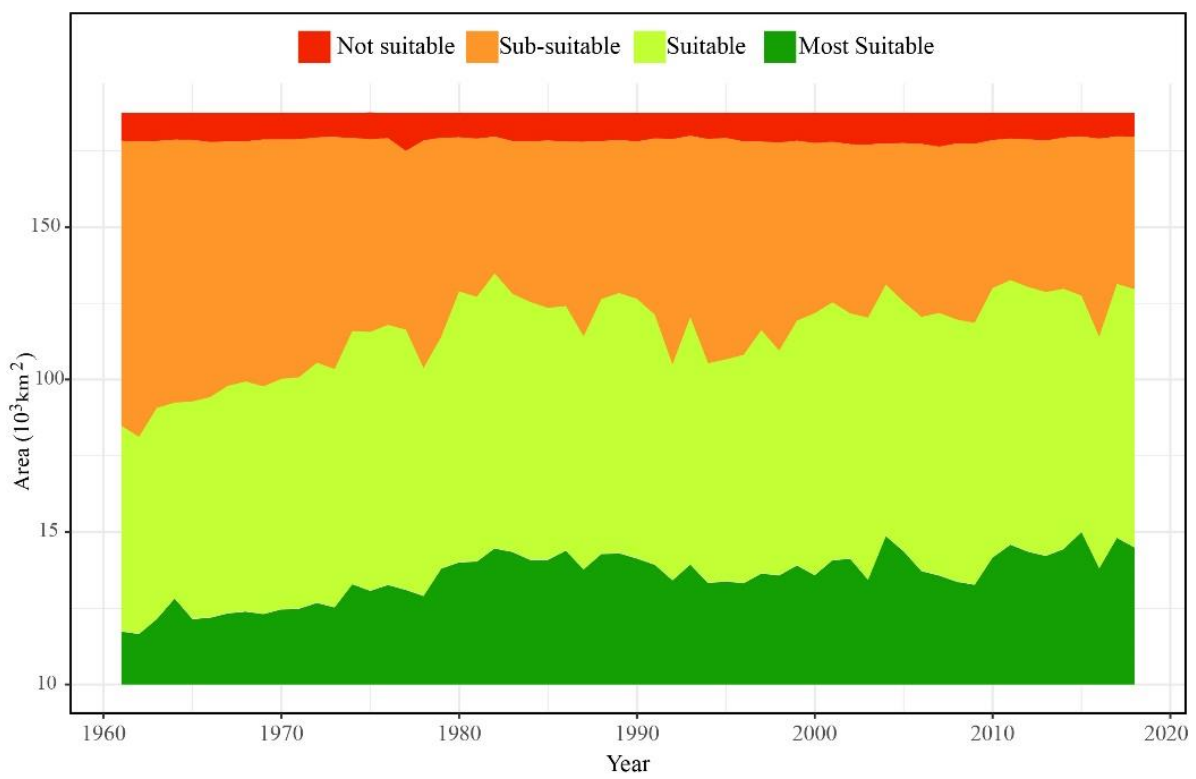

Figure 6. Changes of suitable areas for potato cultivation in Jilin Province.

\section{Discussion and conclusion}

\section{Discussion}

Results obtained from this study show that the increase in the suitability of potato cultivation is more significant in the plains of northwestern Jilin Province than in the mountainous areas of the eastern part. From the perspective of time series comparison, the speed of northward migration and expansion of suitable areas in the later period (1961-1990) was significantly slower than that in the earlier period (1991-2018) (Fig.4). The significant increase in temperature of 
semi-arid regions of the northern low-altitude plains has a great impact on the increase in the suitability of potato cultivation, whereas the influence of warm temperature on the suitability of potato cultivation was relatively small in the eastern mountainous areas near the sea (Fig.5). We found that climate change has expanded the extent of suitable areas for potato cultivation. During the potato growth period (April to September) of 1961-2018 in Jilin Province, AAT showed a significant upward trend, SD showed a downward trend, and PP fluctuated to a large extent without showing an obvious trend. Under the influence of global climate change, the suitable areas for potato cultivation in Jilin Province have been expanding, indicating that the increase in temperature has had a positive impact on the suitability of potato cultivation in Jilin Province over the years, which is consistent with the trend of climatic suitability for potato cultivation ${ }^{40,69}$.

Through the comparative analysis of the distribution of suitable areas for potato cultivation and the dominant potato production areas ${ }^{50}$ in Jilin Province, we found that the current main potato production areas in Jilin Province are mainly included in the "Most suitable" areas, distributed in the center of Jilin Province. This suggests that, more accurate results of suitability zoning were obtained from the current research compared with previous studies on climatic suitability ${ }^{40,53}$ due to the addition of soil factors. The result generated using the evaluation method in this paper, to some extent, can reflect the distribution of suitable areas for potato cultivation.

In addition, it is worth mentioning that not only climate change but also the potato variety, soil fertility, farming system, and production technology $y^{5,21}$ can influence potato growth and development. Further research should consider possible climate change scenarios in the future, in combination with field conditions, irrigation technologies, and other modern measures, to provide a more comprehensive reference for potato cultivation management in Jilin Province. Since potatoes have certain tolerance to temperature and rainfall, as the temperature gets closer and closer to the threshold, the suitability of potato cultivation decreases. When the temperature exceeds the suitable temperate range for potato growth, potato cultivation may be negatively affected by climate change.

From the perspective of geographical distribution, the suitable areas gradually expand to the plains in the northwestern Jilin Province: (i) the sandy soil of the northern region is conducive to the cultivation and production of commercial potatoes; (ii) the mature drip irrigation technology is beneficial to resist adverse effects of increased evaporation caused by future temperature increase; (iii) the transportation condition is convenient and advantageous to the commodity potato transport. Therefore, it is recommended that the future potato industry chain be situated in the northern region of Jilin Province to form a large-scale potato industrial cluster.

\section{Conclusion}

In the current study, the impact of climate change on the spatial distribution of suitable areas for potato cultivation was analyzed, and the temporal and spatial variations of this distribution from 1961 to 2018 were explored. The suitability of potato cultivation in Jilin Province was assessed on the basis of a comprehensive set of criteria associated with the multi-criterion, decision-based AHP-PCA approach. Our results show that the average values of AAT, PP, and SD changed greatly, leading to a change in the climatic suitability of potato production in Jilin Province. Suitable areas for potato cultivation changed little in the middle- and high-altitude mountainous areas in the east, but significant changes in suitable areas were observed in the low-altitude plains in the central and western regions.

From the perspective of spatial distribution, the "Most suitable" areas for potato cultivation are concentrated in the central region of Jilin Province, the "Suitable" areas are distributed in the plains in the northwestern part, the "Subsuitable" areas are mainly located in the eastern mountainous areas, and the "Not suitable" areas occur in the eastern high altitudes. From the perspective of spatio-temporal changes, the impact of key climatic factors on potato cultivation has changed from 1961 to 2018: (i) the climatic suitability of potato cultivation moved northward; (ii) the "Most suitable" and "Suitable" areas for potato cultivation expanded, but the distribution of "Sub-suitable" areas narrowed down.

The area of "Most suitable" areas expanded by $27.51 \times 1,000 \mathrm{~km}^{2}$, and that of "Suitable" areas expanded by 17.27 
$\times 1,000 \mathrm{~km}^{2}$, suggesting that climate change has had a favorable impact on potato cultivation in Jilin Province in the past decades. This research conducted an in-depth analysis of the climate change-induced regional changes in suitable areas for potato production in Jilin Province from a spatio-temporal perspective and provided solid support for potato cultivation to adapt to the new climatic conditions.

\section{References}

1. $\quad$ IPCC. Climate change 2013: The Physical Science Basis Intergovernmental Panel on Climate Change. (Cambridge University Press, Cambridge, 2013).

2. Zhao, X., Wan, J. \& Wu, X. Characteristics of change in temperature during the past 50 years in Jilin province of China. Chin. Geograph.Sc. 12, 329-332 https://doi.org/10.1007/s11769-002-0037-5 (2002).

3. Guo, E., Zhang, J., Wang, Y. et al. Assessing non-linear variation of temperature and precipitation for different growth periods of maize and their impacts on phenology in the Midwest of Jilin Province, China. Theor Appl Climatol. 132, 685-699 https://doi.org/10.1007/s00704-017-2097-6 (2018).

4. Zhao, J. F., X. G. Yang, and Z. J. Liu. Influence of climate warming on serious low temperature and cold damage and cultivation pattern of spring maize in Northeast China. Acta Ecol Sin. 29, 6544-6551 (2009).

5. Yang, Y., Hu, Y., Li, X. et al. Analysis on the Evolution and Driving Factors of the Spatial Pattern of Potato Planting in China. Journal of Agro-technical Economics. 08, 39-47 https://doi.org/10.13246/j.cnki.jae.2017.08.004 (2017).

6. Haverkort, A. J. Ecology of potato cropping systems in relation to altitude and latitude. Agricultural Systems. 32, 251-272 https://doi.org/10.1016/0308-521X(90)90004-A (1990).

7. Lobell, D., Sibley, A. \& Ivan Ortiz-Monasterio, J. Extreme heat effects on wheat senescence in India. Nature Clim Change. 2, 186-189 https://doi.org/10.1038/nclimate1356 (2012).

8. Hatfield JL, Prueger JH. Temperature extremes effect on plant growth and development. Weather and Climate Extremes. 10, 4-10 https://doi.org/10.1016/j.wace.2015.08.001 (2015).

9. El-Ramady, H., Abdalla, N., Alshaal, T. et al. Selenium in soils under climate change, implication for human health. Environ Chem Lett. 13, 1-19 https://doi.org/10.1007/s10311-014-0480-4 (2015).

10. Kukal, M.S., Irmak, S. Climate-Driven Crop Yield and Yield Variability and Climate Change Impacts on the U.S. Great Plains Agricultural Production. Sci Rep. 8, 3450 https://doi.org/10.1038/s41598-018-21848-2 (2018).

11. Liu Y J, Chen Q M, et al. Spatiotemporal differentiation of changes in wheat phenology in China under climate change from 1981 to 2010. Sci. China Earth Sci. 61, 1088-1097 https://doi.org/10.1007/s11430-017-9149-0 (2018).

12. Zheng B., Chapman Scott C., Christopher Jack T., et al. Frost trends and their estimated impact on yield in the Australian wheatbelt, Journal of Experimental Botany. 66, 3611-3623 https://doi.org/10.1093/jxb/erv163 (2015).

13. David, B.L., Wolfram, S., Justin C., Climate trends and global crop production since 1980. Science. 333, 616620 https://doi.org/10.1126/science.1204531 (2011).

14. Ramirez-Cabral NYZ, Kumar L, Taylor S. Crop niche modeling projects major shifts in common bean growing areas. Agric For Meteorol. 218-219, 102-113 https://doi.org/10.1016/j.agrformet.2015.12.002 (2016).

15. Tim Wheeler, Joachim von Braun. Climate change impacts on global food security. Science. 341, 508-513 https://doi.org/10.1126/science.1239402 (2013).

16. Manandhar, S., Pandey, V.P. \& Kazama, F. Assessing suitability of apple cultivation under climate change in mountainous regions of western Nepal. Reg Environ Change. 14, 743-756 https://doi.org/10.1007/s10113-013- 
0531-6 (2014).

17. Zabel F, Putzenlechner B, Mauser W. Global Agricultural Land Resources-A High Resolution Suitability Evaluation and Its Perspectives until 2100 under Climate Change Conditions. PLoS ONE 9, e107522 https://doi.org/10.1371/journal.pone.0107522 (2014).

18. Chemura, A., Kutywayo, D., Chidoko, P. et al. Bioclimatic modelling of current and projected climatic suitability of coffee (Coffea arabica) production in Zimbabwe. Reg Environ Change. 16, 473-485 https://doi.org/10.1007/s10113-015-0762-9 (2016).

19. Chakrabarti SK, Conghua X, Tiwari JK. The Potato Genome. (Springer, Switzerland, 2017).

20. FAOSTAT. Food and agriculture organization of the United Nation Statistics http://www.fao.org/faostat/en/\#home (2020).

21. Luo, S., He, Y., Li, Q. et al. Nondestructive estimation of potato yield using relative variables derived from multi-period LAI and hyperspectral data based on weighted growth stage. Plant Methods. 16, 150 https://doi.org/10.1186/s13007-020-00693-3 (2020).

22. Wang, C., Zang, H., Liu, J. et al. Optimum nitrogen rate to maintain sustainable potato production and improve nitrogen use efficiency at a regional scale in China. A meta-analysis. Agron. Sustain. Dev. 40, 37 https://doi.org/10.1007/s13593-020-00640-5 (2020).

23. Winkler, J.A., Soldo, L., Tang, Y. et al. Potential impacts of climate change on storage conditions for commercial agriculture: an example for potato production in Michigan. Climatic Change. 151, 275-287 https://doi.org/10.1007/s10584-018-2301-4 (2018).

24. Yagiz, A.K., Cakici, M., Aydogan, N. et al. Exploration of Climate Change Effects on Shifting Potato Seasons, Yields and Water Use Employing NASA and National Long-Term Weather Data. Potato Res. 63, 565-577 https://doi.org/10.1007/s11540-020-09457-x (2020).

25. Sanabria, J., Lhomme, J.P. Climate change and potato cropping in the Peruvian Altiplano. Theor Appl Climatol. 112, 683-695 https://doi.org/10.1007/s00704-012-0764-1 (2013).

26. Leisner, C.P., Wood, J.C., Vaillancourt, B. et al. Impact of choice of future climate change projection on growth chamber experimental outcomes: a preliminary study in potato. Int J Biometeorol. 62, 669-679 https://doi.org/10.1007/s00484-017-1475-1 (2018).

27. Tang, J., Xiao, D., Bai, H. et al. Potential Benefits of Potato Yield at Two Sites of Agro-Pastoral Ecotone in North China Under Future Climate Change. Int. J. Plant Prod. 14, 401-414 https://doi.org/10.1007/s42106$\underline{020-00092-7}$ (2020).

28. Rana, A., Dua, V.K., Chauhan, S. et al. Climate Change and Potato Productivity in Punjab-Impacts and Adaptation. Potato Res. 63, 597-613 https://doi.org/10.1007/s11540-020-09460-2 (2020).

29. Holzkämper A, Calanca P, Fuhrer J. Analyzing climate effects on agriculture in time and space. Mapp. Glob. Change. 3, 58-62 https://doi.org/10.1016/j.proenv.2011.02.011 (2011).

30. Li, C., Tang, Y., Luo, H. et al. Local Farmers' Perceptions of Climate Change and Local Adaptive Strategies: A Case Study from the Middle Yarlung Zangbo River Valley, Tibet, China. Environmental Management. 52, 894906 https://doi.org/10.1007/s00267-013-0139-0 (2013).

31. Ray, D., Gerber, J., MacDonald, G. et al. Climate variation explains a third of global crop yield variability. Nat Commun. 6, 5989 https://doi.org/10.1038/ncomms6989 (2015).

32. Rosenzweig C, Phillips J, Goldberg R, et al. Potential impacts of climate change on citrus and potato production in the US. Agricultural Systems. 52, 455-479 https://doi.org/10.1016/0308-521X(95)00059-E (1996).

33. Rubí Raymundo, Senthold A., Richard R. et al. Climate change impact on global potato production. European 
Journal of Agronomy. 100, 87-98 https://doi.org/10.1016/j.eja.2017.11.008 (2018).

34. Davies A., et al. Modelling the predicted geographic and economic response of UK cropping systems to climate change scenarios: the case of potatoes. Annals of Applied Biology https://10.1111/j.17447348.1997.tb05792.x (1997).

35. Bender, F.D., Sentelhas, P.C. Assessment of Regional Climate Change Impacts on Brazilian Potato Tuber Yield. Int. J. Plant Prod. 14, 647-661 https://doi.org/10.1007/s42106-020-00111-7 (2020).

36. Hijmans, R.J. The effect of climate change on global potato production. Am. J. Pot Res. 80, 271-279 https://doi.org/10.1007/BF02855363 (2003).

37. Zhao, J., Yang, X., Liu, Z. et al. Variations in the potential climatic suitability distribution patterns and grain yields for spring maize in Northeast China under climate change. Climatic Change. 137, 29-42 https://doi.org/10.1007/s10584-016-1652-y (2016).

38. Manandhar, S., Pandey, V.P. \& Kazama, F. Assessing suitability of apple cultivation under climate change in mountainous regions of western Nepal. Reg Environ Change. 14, 743-756 https://doi.org/10.1007/s10113-013$\underline{0531-6}$ (2014).

39. Bozdağ, A., Yavuz, F. \& Günay, A.S. AHP and GIS based land suitability analysis for Cihanbeyli (Turkey) County. Environ Earth Sci. 75, 813 https://doi.org/10.1007/s12665-016-5558-9 (2016).

40. Wang C., Li H., Zeng J., et al. Spatial and Temporal Changes of Climatic Suitability of Potato in Semi-arid Region of Loess Plateau. Journal of Arid Meteorology. 35, 751-760 (2017).

41. Irimia, L.M., Patriche, C.V., Quenol, H. et al. Shifts in climate suitability for wine production as a result of climate change in a temperate climate wine region of Romania. Theor Appl Climatol. 131, 1069-1081 https://doi.org/10.1007/s00704-017-2033-9 (2018).

42. Kim SO, Chung UR, Kim SH, et al. The suitable region and site for 'Fuji' apple under the projected climate in South Korea. Korean J Agric Forest Meteorol. 11, 162-173 https://doi.org/10.5532/KJAFM.2009.11.4.162 (2009).

43. Duan, Y., Liu, J., Xu, J. et al. DNA Fingerprinting and Genetic Diversity Analysis with Simple Sequence Repeat Markers of 217 Potato Cultivars (Solanum tuberosum L.) in China. Am. J. Potato Res. 96, 21-32 https://doi.org/10.1007/s12230-018-9685-6 (2019).

44. Han Z., Zhang S., Yu C., et al. The Difference of Photosynthetic Characteristics of Different Mature Potatoes under Facility. Journal of Northeast Normal University (Natural Science edition). 49, 112-115 https://doi.org/10.16163/j.cnki.22-1123/n.2017.03.023 (2017).

45. Luo S., et al. Analysis of hyperspectral variation of different potato cultivars based on continuum removed spectra. Spectrosc Spec Anal. 38, 3231-7 https://doi.org/10.3964/j.issn.1000-0593(2018)10-3231-07 (2018).

46. Duan D., et al. Analysis on the ability of distinguishing potato varieties with different hyperspectral parameters. Spectrosc Spec Anal. 38, 3215-20 https://doi.org/10.3964/j.issn.1000-0593(2018)10-3215-06 (2018).

47. Liu T., Yang X., Gao J., et al. Production capacity and its WUE of different crops in Lishu county of Jilin Province. Transactions of the CSAE. 35, 97-104 https://doi.org/10.11975/j.issn.1002-6819.2019.07.012 (2019).

48. Li YJ., Gen W., et al. Nutrition characteristics and Development Prospect of potato translation. China Fruit \& Vegetable. 37, 16-17+20 https://doi.org/10.11975/j.issn.1002-6819.2019.07.012 (2017).

49. Zhou T., Liu J. The Distribution and Developmental Patterns of Agricultural Products Processing Industry Cluster in Jilin Province. Scientia Geographica Sinica. 33, 815-823 https://doi.org/10.13249/j.cnki.sgs.2013.07.006 (2013).

50. Jilin Bureau of Statistics. Jilin statistical yearbooks. (China Statistics Press, Beijing, 2019) 
51. Zhang, H., \& Shan, B. Historical records of heavy metal accumulation in sediments and the relationship with agricultural intensification in the Yangtze-Huaihe region, China. Science of the Total Environment. 399, 113120 https://doi.org/10.1016/j.scitotenv.2008.03.036 (2008).

52. Wang Z., et al. Variety Identification of Potatoes based on Canopy Hyperspectral Data and Mahalanobis Distance. Jiangsu J. of Agr. Sci. 34, 1036-1041 https://doi.org/10.3969/j.issn.1000-4440.2018.05.010 (2018).

53. Chi Zaixiang, Mo Jianguo, Kang Xueliang, et al. Regionalization of the climate suitability on spring potato planting in Western Guizhou based on GIS. Chinese Agricultural Meteorology. 33, 93-97 (2012).

54. Thornton PE, Running SW, White MA. Generating surfaces of daily meteorological variables over large regions of complex terrain. J Hydrol. 190, 214-251 https://doi.org/10.1016/S0022-1694(96)03128-9 (1997).

55. Liu Y, et al. A Spatial Interpolation Method for Surface Air Temperature and Its Error Analysis. Chin JAtmos Sci. 30, 146-152 https://doi.org/10.1016/S1003-6326(06)60040-X (2006).

56. Esri Core Team. ArcGIS: Geo-Information system Mapping Software Spatial Data Analytics \& Location. Environmental Systems Research Institute, Inc. American. https://desktop.arcgis.com/en (2017).

57. R Development Core Team. R: A language and environment for statistical computing. R Foundation for Statistical Computing, Vienna. https://www.r-project.org (2020).

58. Thornton PE, Running SW. An improved algorithm for estimating incident daily solar radiation from measurements of temperature, humidity, and precipitation. Agr Forest Meteorol. 93, 211-228 https://doi.org/10.1016/S0168-1923(98)00126-9 (1999).

59. Wu Guanghe. Physical Geography Fourth Edition. (Higher Education Press, Beijing, 2008).

60. Chen PX., Mao WY. Research on the rasterization method of Xinjiang temperature data based on GIS. Arid Land Geography. 35, 438-445 (2012).

61. Saaty TL. The analytical hierarchy process. (McGraw Hill, New York, 1980).

62. Michele, Bernardi. Linkages between FAO agroclimatic data resources and the development of GIS models for control of vector-borne diseases. Acta Tropica. 79, 21-34 https://doi.org/10.1016/S0001-706X(01)00100-0 (2001).

63. Jolliffe, I. T. Principal component analysis, Springer series in statistics (2nd ed.). (Springer, Berlin, 2002).

64. Mistri, P., Sengupta, S. Multi-criteria Decision-Making Approaches to Agricultural Land Suitability Classification of Malda District, Eastern India. Nat Resour Res. 29, 2237-2256 https://doi.org/10.1007/s11053019-09556-8 (2020).

65. Zhang, J., et al. GIS based land suitability assessment for tobacco production using AHP and fuzzy set in Shandong Province of China. Computers and Electronics in Agriculture. 114, 202-211 https://doi.org/10.1016/j.compag.2015.04.004 (2015).

66. Chen Y, Yu J, Khan S. Spatial sensitivity analysis of multi-criteria weights in GIS-based land suitability evaluation. Environ Model Softw. 25, 1582-1591 https://doi.org/10.1016/j.envsoft.2010.06.001 (2010).

67. Santer BD, et al. Statistical significance of trends and trend differences in layer-average atmospheric temperature time series. Journal of Geophysical Research. 105, 7337-7356 https://doi.org/10.1029/1999jd901105 (2000).

68. Dobrowski SZ, et al. The climate velocity of the contiguous United States during the 20th century. Global Change Biology. 19, 241-251 https://doi.org/10.1111/gcb.12026 (2013).

69. Liao XP, et al. Distribution Response of Winter Potato Planting to Climate Warming in Guangxi. Journal of Southwest Agriculture. 06, 2311-2315 (2014). 


\section{Acknowledgments}

620 This research is supported by the Soft Science Project of Rural Revitalization Expert Advisory Committee, Ministry of 621 Agriculture and Rural Areas, Central Agricultural Affairs Office (code: 20190206; 2019KF116) and the Special Funds 622 for Basic Scientific Research, Central Public-interest Scientific Institution (code: Y2018YJ26; Y2019ZK10; G202002623 48). We thank TopEdit for its linguistic assistance during the preparation of this manuscript.

\section{Author contributions}

Q.Y and Y.Y conceived and designed the study; Y.Y. and Y.Z. collected the data; Y.Z. conducted the GIS analyses; Y.Y. led the modelling analyses and discussed results with Q.L. and Q.Y.; Y.Z. wrote the original draft; J.Z., H.Z., Z.J. and Y.D. reviewed \& edited; All the authors jointly developed the final set of analyses and contributed to the writing and editing of the manuscript.

\section{Competing interests}

The authors declare no competing interests. 


\section{Figures}

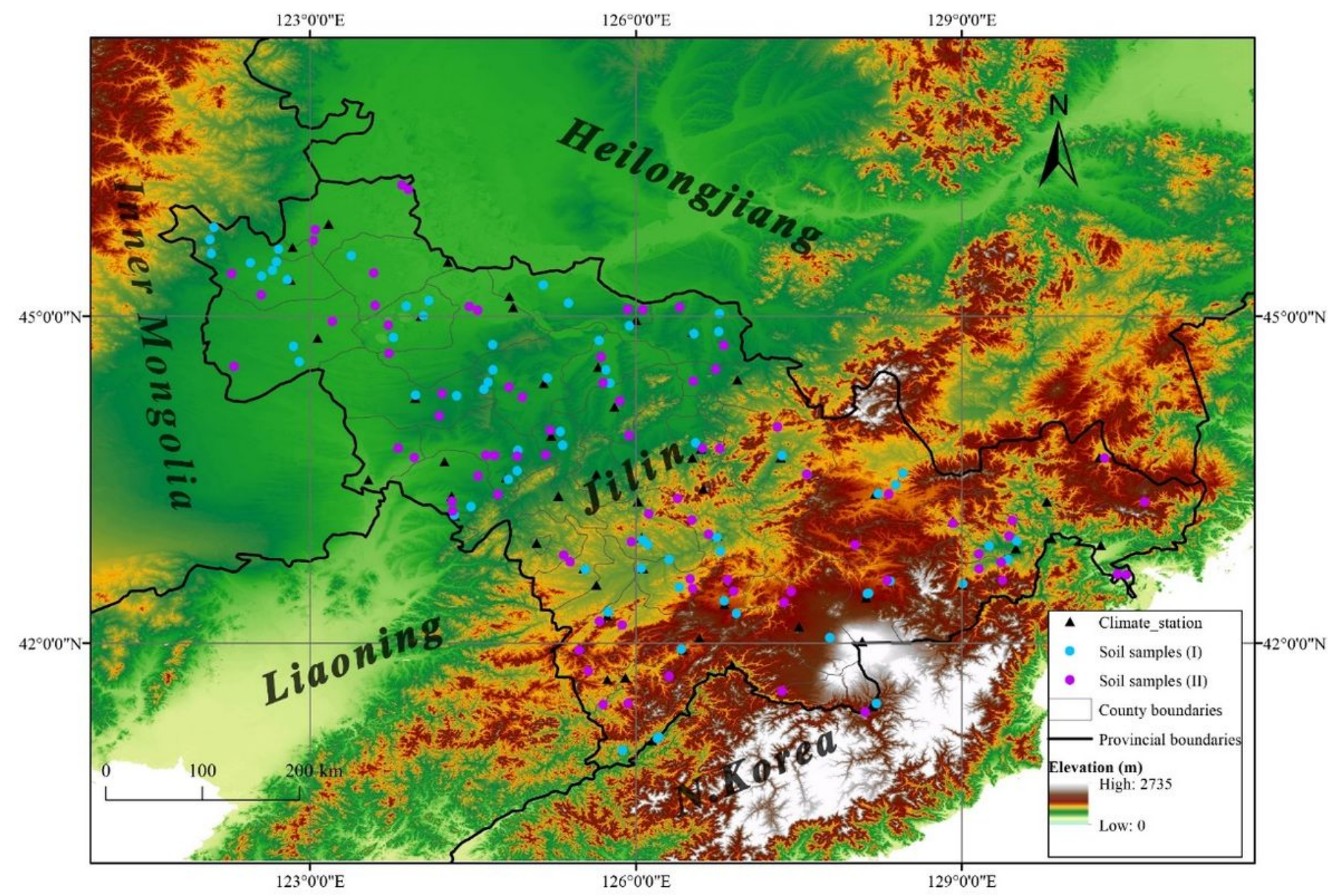

\section{Figure 1}

Spatial distribution of 51 meteorological stations and soil sampling sites in the study area. Soil data were divided into two categories. Soil samples (I): soil mechanical compositions, involving 81 sampling points; soil samples (II): soil physico-chemical properties, involving 79 sampling points. Note: The designations employed and the presentation of the material on this map do not imply the expression of any opinion whatsoever on the part of Research Square concerning the legal status of any country, territory, city or area or of its authorities, or concerning the delimitation of its frontiers or boundaries. This map has been provided by the authors. 


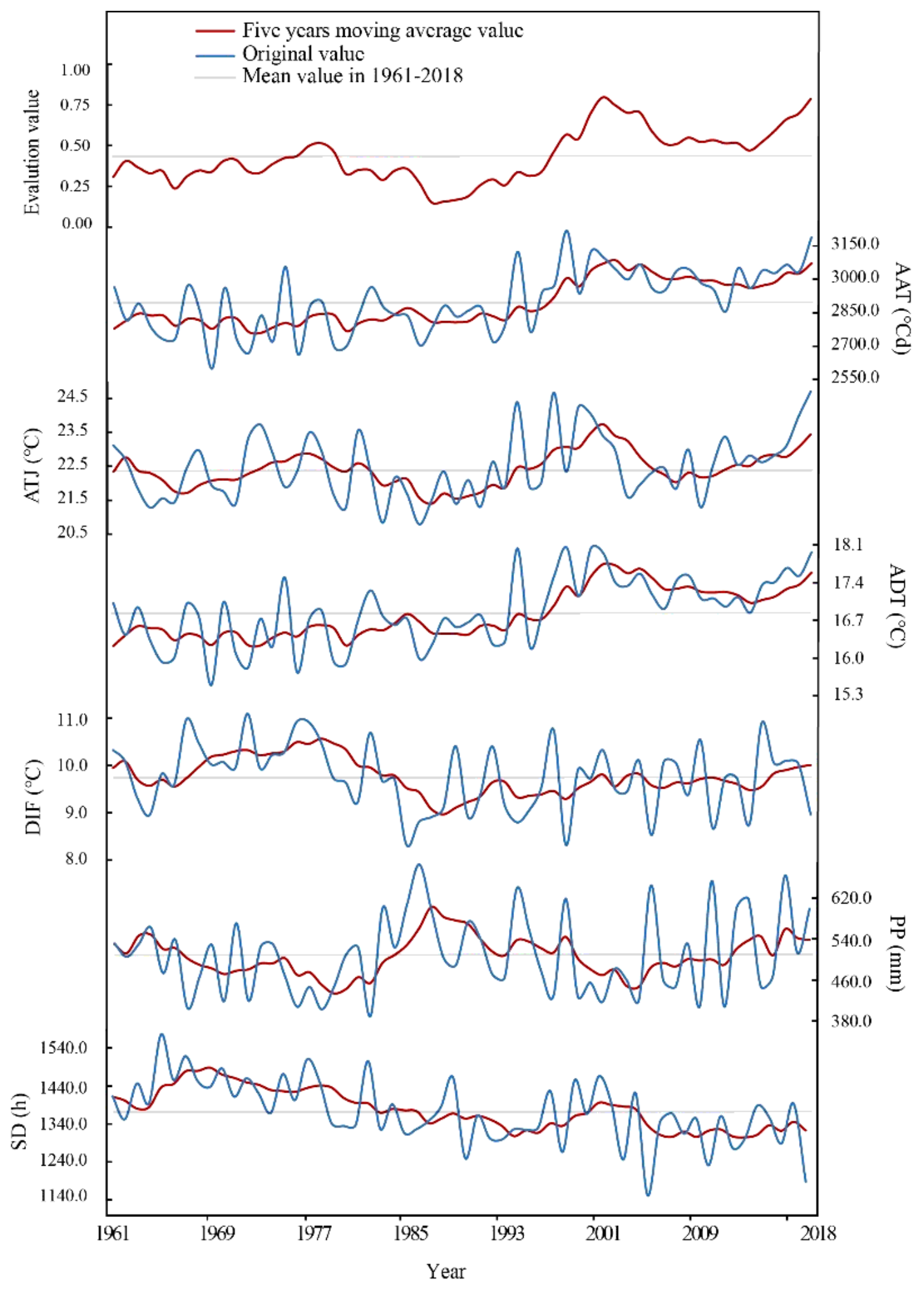

Figure 2

Inter-annual variation trends of climatic factors and evaluation values in the study area from 1961 to 2018. ADT: average daily temperature during the growth period ( () ; AAT: sum of active accumulated

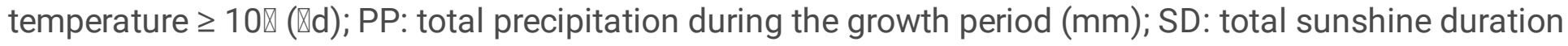
during the growth period (h); ATJ: average temperature in July (『); DIF: the day/night temperature difference from July to August ( () . 

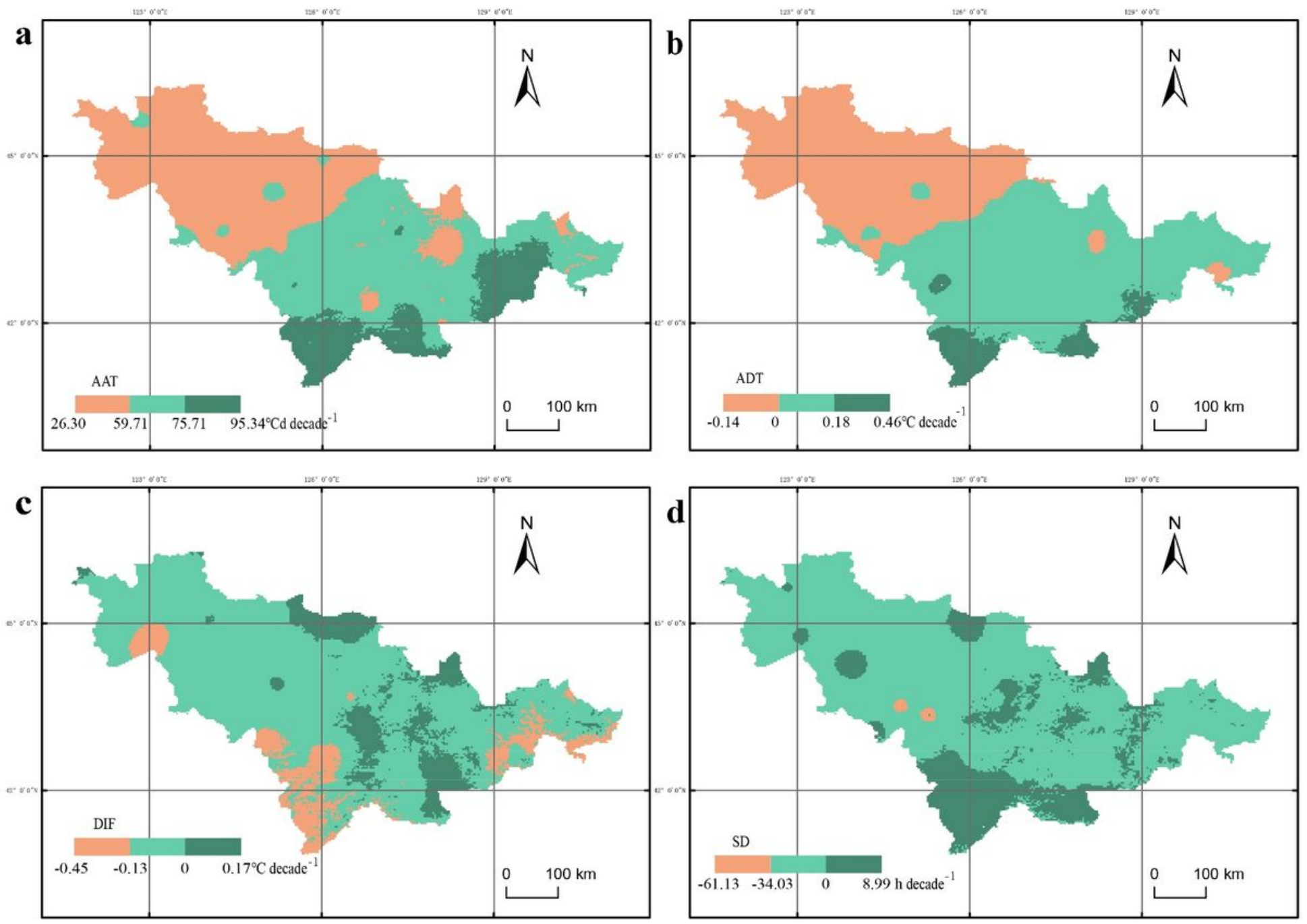

Figure 3

Maps for spatial distribution of climate inclination rates varied across Jilin Province from 1961 to 2018.

(a) The active accumulated temperature of $\geq 10 \bigotimes$. (b) Average daily temperature during the growth period.

(c) The average day/night temperature difference from July to August. (d) Sunshine durations. Note: The designations employed and the presentation of the material on this map do not imply the expression of any opinion whatsoever on the part of Research Square concerning the legal status of any country, territory, city or area or of its authorities, or concerning the delimitation of its frontiers or boundaries. This map has been provided by the authors. 


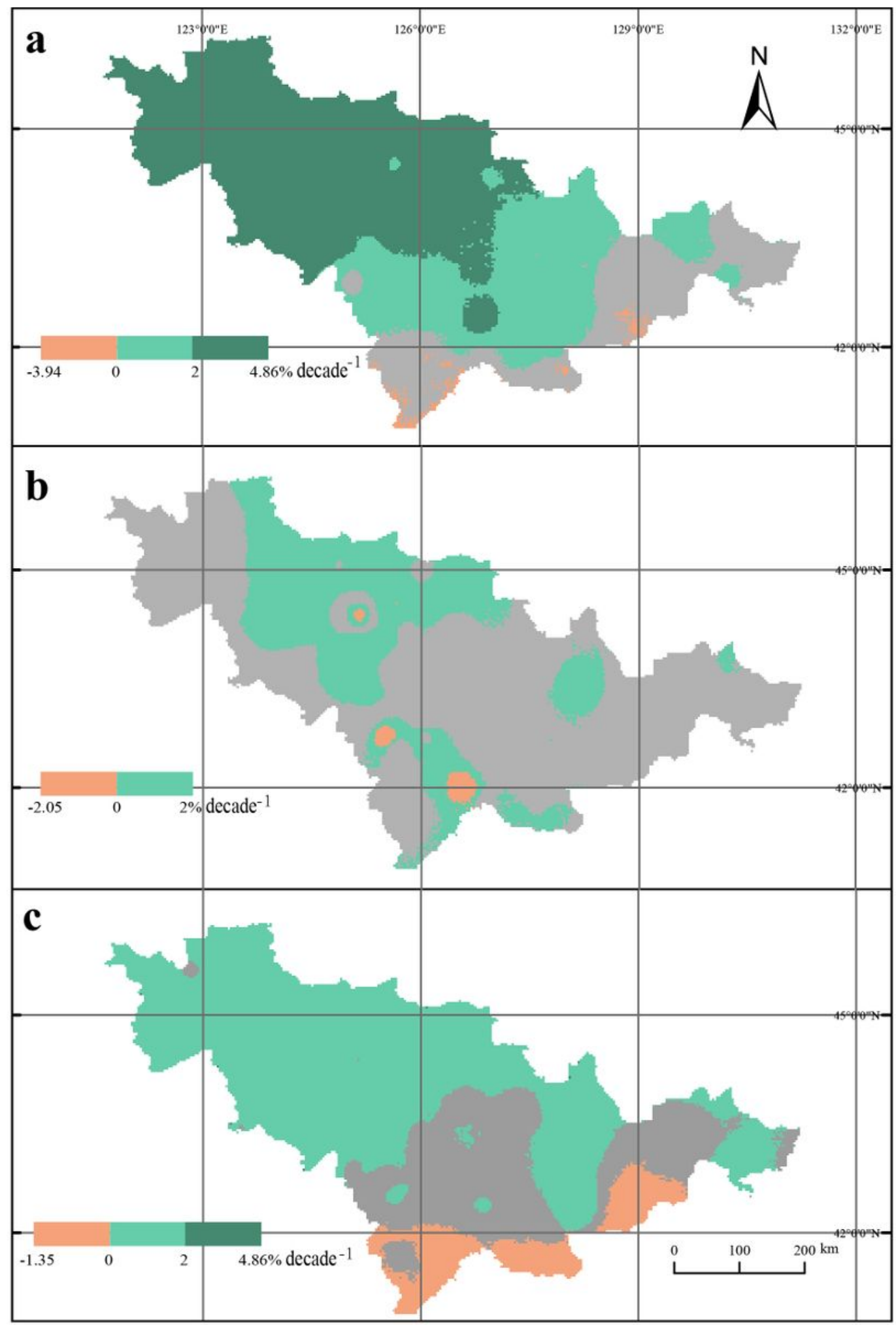

Figure 4

Maps for trends in climate-driven suitability zonation across Jilin Province from 1957 to 2018. (a) 19611988; (b) 1988-2018; (c) 1961-2018. The grey shades in (a-c) indicate the regions where trends in area change of suitability zonation failed the significance test $(P>0.1)$. Note: The designations employed and the presentation of the material on this map do not imply the expression of any opinion whatsoever on the part of Research Square concerning the legal status of any country, territory, city or area or of its 
authorities, or concerning the delimitation of its frontiers or boundaries. This map has been provided by the authors.

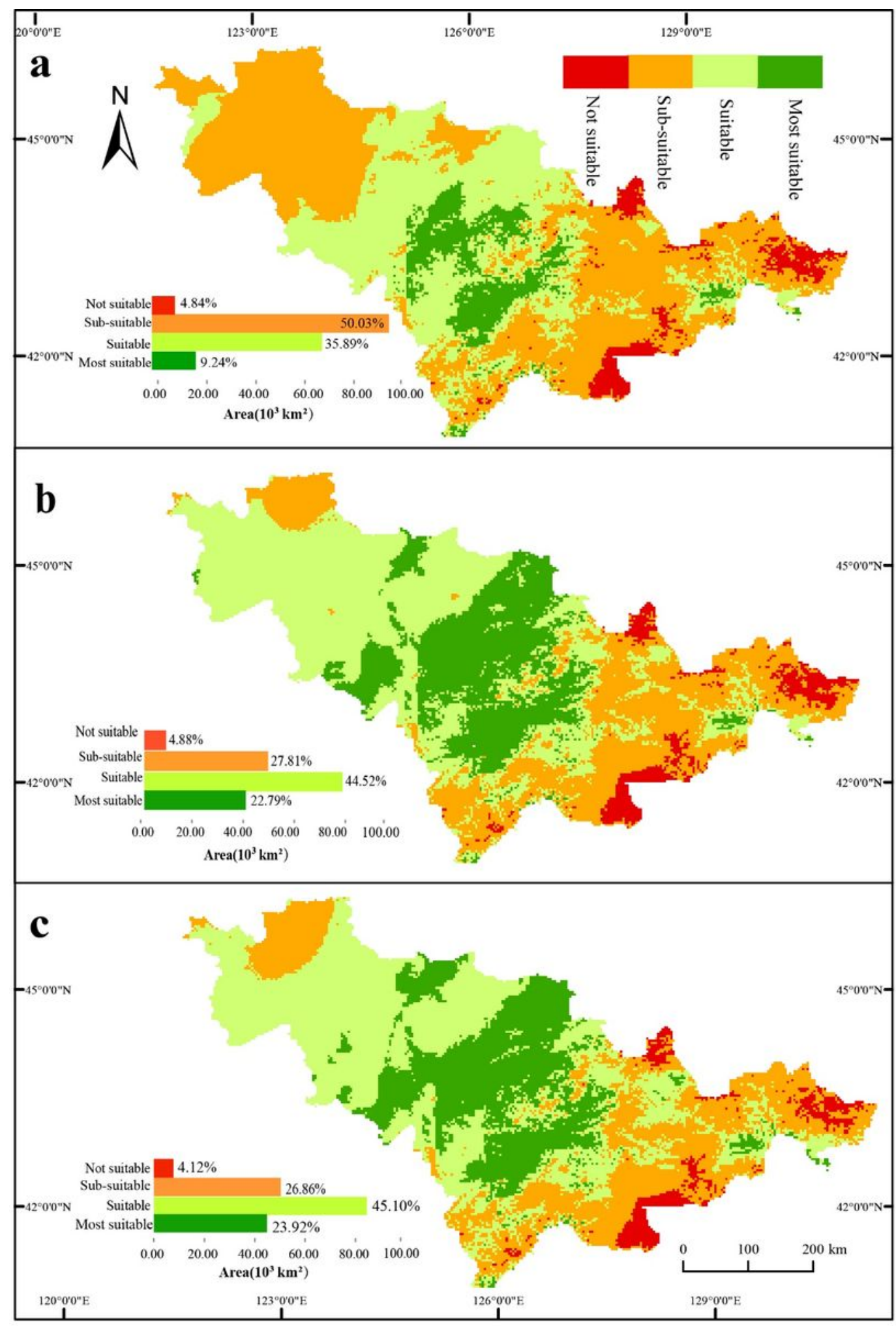

Figure 5

Maps for spatio-temporal changes in the distribution of suitability zonation for potato cultivation in Jilin Province. (a) In 1961, the areas of "Not suitable", "Sub-suitable", "Suitable", and "Most suitable" areas were $9.08 \times 103,93.76 \times 103,67.25 \times 103$, and $17.31 \times 103 \mathrm{~km} 2$, respectively. (b) In 1988, the areas of 
"Not suitable", "Sub-suitable", "Suitable", and "Most suitable" areas were $9.15 \times 103,52.11 \times 103,83.42 \times$ 103, and $42.71 \times 103 \mathrm{~km} 2$, respectively. (c) In 2018, the areas of "Not suitable", "Sub-suitable", "Suitable", and "Most suitable" areas were $7.72 \times 103,50.33 \times 103,84.53 \times 103$, and $44.82 \times 103 \mathrm{~km} 2$, Note: The designations employed and the presentation of the material on this map do not imply the expression of any opinion whatsoever on the part of Research Square concerning the legal status of any country, territory, city or area or of its authorities, or concerning the delimitation of its frontiers or boundaries. This map has been provided by the authors. respectively.

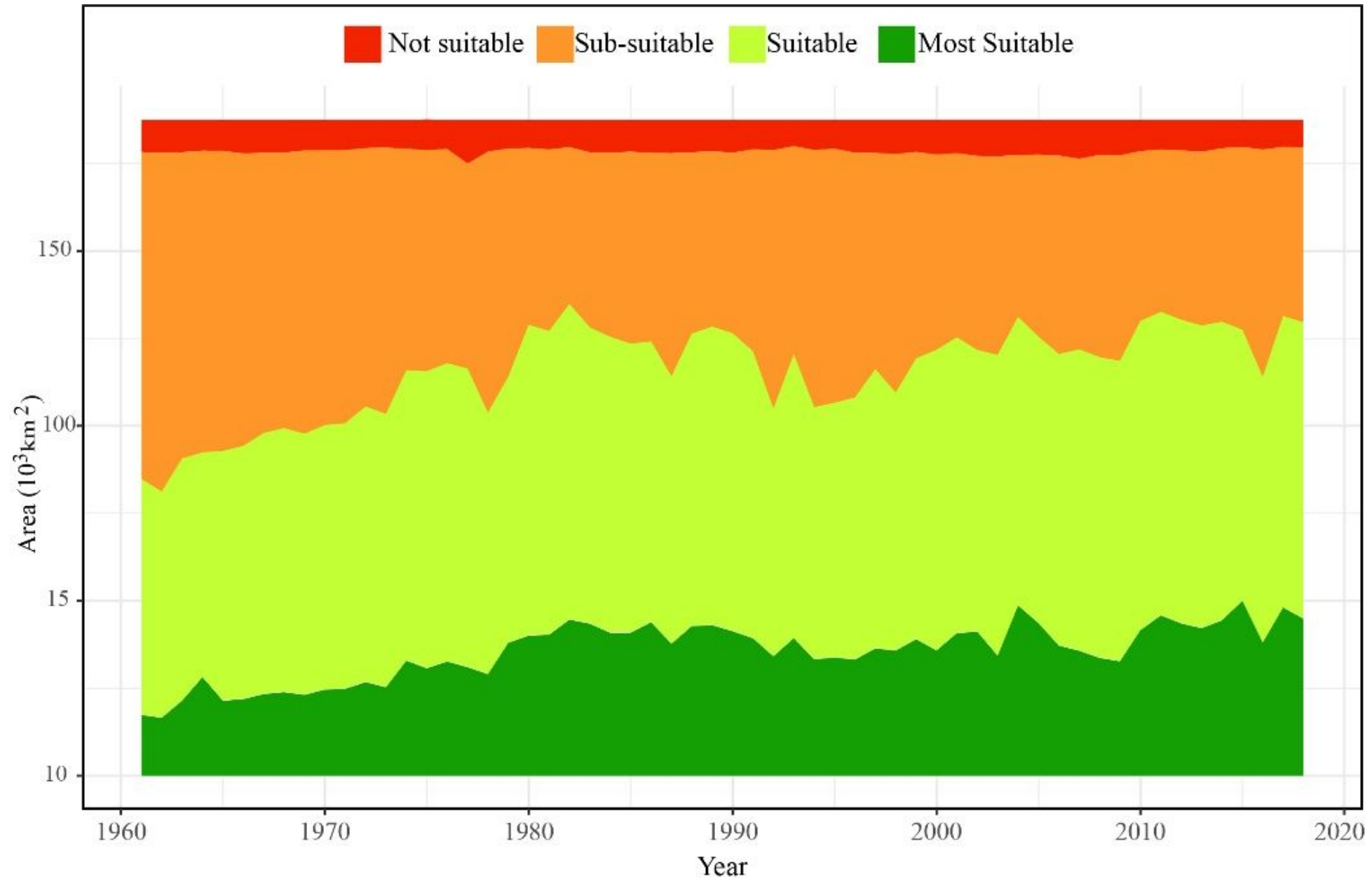

Figure 6

Changes of suitable areas for potato cultivation in Jilin Province.

\section{Supplementary Files}

This is a list of supplementary files associated with this preprint. Click to download.

- Supplementarylnformation.pdf 